Review Article

\title{
Environmental Concerns and Toxicogenetic Endpoints of Priority Substances (PSs) and Contaminants of Emerging Concerns (CECs): A Comprehensive Review
}

\author{
${ }^{1,2^{*}}$ Yi Liu, ${ }^{1,2^{*}}$ Muhammad Junaid, ${ }^{1,2}$ Naima Hamid, ${ }^{1}$ Chun-Di Chen and ${ }^{1}$ De-Sheng Pei \\ ${ }^{1}$ Key Laboratory of Reservoir Aquatic Environment, \\ Chongqing Institute of Green and Intelligent Technology, Chinese Academy of Sciences, Chongqing 400714, China \\ ${ }^{2}$ University of Chinese Academy of Sciences, Beijing 100049, China
}

\begin{abstract}
Article history
Received: 14-05-2018

Revised: $15-05-2018$

Accepted: 06-07-2018

Corresponding Author: De-Sheng Pei

Key Laboratory of Reservoir Aquatic Environment, Chongqing Institute of Green and Intelligent Technology, Chinese Academy of Sciences, Chongqing 400714, China Emails: peids@cigit.ac.cn deshengpei@gmail.com

*These authors contributed equally to this work.
\end{abstract}

\begin{abstract}
Priority Substance (PSs) and Contaminant of Emerging Concerns (CECs) exhibited a wide range of environmental and public health concerns worldwide. This review summarized the documented studies related to the current surface water occurrence, spatial distribution, ecological risks and toxicity of selected PSs, such as polycyclic aromatic hydrocarbons (PAHs) and CECs, such as Di(2-Ethylhexyl) Phthalate (DEHP) and Pharmaceuticals and Personal Care Products (PPCPs). The spatial distribution analysis revealed alarming levels of PAHs in the surface waters of Asian counties, e.g., $84210 \mathrm{ng}$ $\mathrm{L}^{-1}$ in Gomti River, India, $29325 \mathrm{ng} \mathrm{L}^{-1}$ in Daya Bay, China and $1287 \mathrm{ng} \mathrm{L}^{-1}$ in Chenab River, Pakistan. As for DEHP, the highest concentrations of $13050 \mu \mathrm{g}$ $\mathrm{L}^{-1}$ in Liao River, China, and $2306 \mu \mathrm{g} \mathrm{L}^{-1}$ in Rivers of Eastern Cape, South Africa were reported. These environmental levels of PAHs and DEHP were many folds higher than the surface water permissible levels devised by WHO and USEPA. Contrarily, the emerging PPCPs were reported in relatively lower levels in the surface waters globally, compared to that of PAHs and DEHP. Consistent with the environmental levels, PAHs and DEHP revealed alarming ecological risks in the surface water sources, compared to that of PPCPs. Regarding to the sources of PSs and CECs, PAHs emissions were mostly linked to the incomplete combustion of petroleum products, DEHP contamination was associated to its applications in consumption and production of plastic appliances and PPCPs emissions were largely related to the domestic and industrial effluents. As for toxic endpoints of PAHs, DEHP and PPCPs, all of these were reported to cause DNA damage, genotoxicity, reproductive toxicity, developmental toxicity and immunotoxicity, as revealed in reviewed in vitro/vivo studies. In addition, the current review also highlighted the existing environmental regulations to control the emissions of these pollutants to the environmental matrices. Taken together, this review concluded that despite the existing environmental regulations, the current levels of organic pollutants are still on rising, especially in Asian countries. Therefore, the strict implementation of the existing regulations is highly necessary to control these pollutants to ensure public health and ecological integrity.
\end{abstract}

Keywords: PAHs, DEHP, PPCPs, Environmental Occurrence, Ecological Risks, Toxicity

\section{Background Information}

Recent population growth and rapid economic development have imposed immense pressures on environmental resources, including the deteriorated water quality, worldwide (Han et al., 2016). Despite the serious threat to the freshwater resources, the water quality grading system still largely depends on the concentrations of basic organic pollution indicators, such as Biological Oxygen Demand (BOD) and Chemical 
Oxygen Demand (COD) and inorganic contaminants such as ammonia $\left(\mathrm{NH}_{4}\right)$, phosphate $\left(\mathrm{PO}_{4}\right.$ and heavy metals (Han and Currell, 2016). Generally, baseline data are still elusive on the specific classes of organic pollutants, despite the fact that the past-half century has been capitalized by scientists all over the world to investigate environmental hazards of Persistent Organic Pollutants (POPs) (Loganathan and Lam, 2012), especially after the Stockholm Convention (UNEP, 2009) and Aarhus Protocol on POPs (UNECE, 1998). Water pollution decreases the availability of freshwater resources, which in return increases the pressure on demand, especially in the countries that have limited sources of fresh water, such as China. China has about one-fifth of the world's population, but only retains $5 \%$ $\left(2.73 \times 10^{12} \mathrm{~m}^{3}\right)$ of world's freshwater resources (MWR, 2015). This situation is not limited to China, many other countries are also facing serious challenges to control water pollution and overcome the water scarcity (Gleick, 2009). Di(2-Ethylhexyl) Phthalate (DEHP), Polycyclic Aromatic Hydrocarbons (PAHs) and Pharmaceuticals and Personal Care Products (PPCPs) are known as Priority Substances (PSs)/contaminants of emerging concerns (CECs), usually present in $\mathrm{ng} / \mathrm{L}$ to $\mu \mathrm{g} / \mathrm{L}$ concentrations in the aquatic environment. They have shown alarming ecotoxicological concerns in recent years (Sousa et al., 2017; Tijani et al., 2016). These ubiquitous compounds have pseudo-persistent behavior and also have potentials to trigger adverse toxicological effects due to their continuous introduction into the water resources (Wilkinson et al., 2017).

\section{Existing Regulations for Priority Substances (PSs) and Contaminants of Emerging Concerns (CECs)}

Based on the presence or absence of regulations, the organic pollutants are classified as PSs or CECs (Gorito et al., 2017; Sousa et al., 2017). A European environmental legislative body Water Framework Directive (WFD) defines PSs as "presenting a significant risk to or via the aquatic environment" and includes compounds, such as PAHs, Polychlorinated Biphenyls (PCBs) and etc. CECs comprise several types of compounds, such as PPCPs, phthalates and etc. (WFD, 2000). Previously, it wasn't pre-requisite to perform chemical analysis of PSs and CECs in the water bodies for environmental regulation (Tiedeken et al., 2017). However, increasing environmental concerns of these contaminants in the aquatic resources have greatly acknowledged their qualitative and quantitative analysis for the regulatory purpose to improve water quality and WFD has recommended continuous monitoring of these organic pollutants for all of the EU countries (WFD, 2015). The environmental regulation of PSs in the surface waters dated back to the year 2000, when WFD
(2000/60/EC) launched a water policy framework to identify some chemicals that need to monitor in the environment to provide necessary mitigation measures (WFD, 2000). In the same year, The Stockholm Convention on POPs was first signed in 2001 $(2455 / 2001 / E C)$ that later adopted to EU legislation in $2004(850 / 2004)$ and also ratified by 180 countries (UNEP, 2009). Five years later, the first list of Environmental Quality Standards (EQS) was published by WFD (2008/105/EC) for basic water quality parameters and that list was later revised in 2013 for PSs (2013/39/EU) (WFD, 2013). The PSs, e.g., PAHs, pharmaceuticals and pesticides have been added to Annex A by WFD in 2013 and monitoring of these PSs declared compulsory in surface waters and article 16(4) of this legislation bounded the EU member states to revise the list of these PSs and their levels shall not exceed the threshold values (WFD 2013).

United States Environmental Protection Agency (USEPA) classified DEHP as a top-priority environmental pollutant and also listed it as B2 class compound (probable human carcinogen) (USEPA, 2000). Further, Agency for Toxic Substances and Disease Registry (ATSDR) also categorized DEHP as an epigenetic toxicant and an endocrine disruptor (ATSDR, 2002). EU also banned the use of six phthalates including DEHP in plastics in 2005 (EU, 2008). In the U.S., similar kinds of efforts were made in 2008 to ban phthalates (Magdouli et al., 2013). In 2000, the Ministry of Health and Welfare of Japan also restricted the use of DEHP in plastics (Suzuki et al., 2001; Tsumura et al., 2003). WFD categorized DEHP as PSs (WFD, 2013) due to the various factors, such as high detection frequency and persistence in environmental compartments (Luo et al., 2014) and augmented toxicity and bioaccumulation in aquatic species (Sousa et al., 2017). PAHs were also declared as PSs by ATSDR and WFD a long-time ago (ATDSR, 1995; WFD, 2000) and PAHs exhibited fused aromatic ring structure with mutagenic and carcinogenic properties, long-half lives and potential to generate heteroaromatic hydrocarbons after chemical reactions (Kafilzadeh, 2015; Nagy et al., 2013).

U.S. Food and Drug Administration (FDA) implemented the ecological risk assessment (ERA) for pharmaceuticals under the National Environmental Policy Act (NEPA) (FDA, 1969) and later Center for Drug Evaluation and Research (CDER) established the guidelines for a tiered risk assessment method (CDER, 1998). In the same year, USEPA enacted regulations for pharmaceutical industry to control their both air emissions and effluent discharges (USEPA, 1998). In 2006, European Medicine Agency (EMA) devised the first guidelines for ERA for human pharmaceuticals (EMA, 2006). Similarly, Australian Therapeutic Goods Administration (ATGA) devised the regulations and ERA for newly registered PPCPs (TGA, 2008). China 
promulgated the Environmental Management Methods (EMMs) for newly produced chemicals in 2010 and recently in 2013. Recently, another similar regulation, "Environmental Management and Registration Method for Hazardous Chemicals" (MEP's order 22), was also formulated (MEP, 2010; 2012). The ingredients of drugs (including that of NSAIDs) and personal care products (PCPs) have been regulated under these laws. The livestock wastes comprising veterinary drugs and effluents have been also regulated by Ministry of Environment Protection (MEP), China (MEP, 2001). Further, the wastewater discharge containing 16 different types of pharmaceuticals, such as Ibuprofen (IBU), Sulfadiazine (SDZ) and Caffeine (CAF), have been regulated in China (MEP, 2008). Recently, WFD recommended to establish water treatment strategies and monitor 54 PSs including 49 organic pollutants and 4 metals (WFD, 2015). For CECs, no definite EQS are existed, however, the previous studies have suggested a prioritization system based on two indicators, the extent of exceedance and the frequency of exceedance of predicted no effect concentrations (PNECs) (Ohe and Dulio, 2013; Tiedeken et al., 2017). Recently, WFD has listed 17 CECs to their Watch List (Decision 2015/495/EU), including five pharmaceuticals, such as erythromycin (ERY) and Diclofenac (DIC), etc. (WFD, 2015). DIC belongs to nonsteroidal anti-inflammatory (NSAIDs), which is of great concern due both to the largest over-the-counter drugs and their wide administration as pain relievers, worldwide (Shanmugam et al., 2014). Altogether, this section clearly listed the major global and local regulations to control the emissions of PSs and CECs.

\section{Sources of DEHP, PAHs and PPCPs}

The major sources of DEHP, PAHs and PPCPs are illustrated in Fig. 1. To track the diverse sources of organic pollutants is of immense importance to implement control measures and source base regulations (Ribeiro et al., 2016). Different industrial processes, such as raw material processing, manufacturing and distribution, are the possible sources of organic pollutants (Barbosa et al., 2016a). Multiple sources of DEHP have been reported in the literature based on its widespread applications and detection across different environmental compartments (Fig. 1A). DEHP releases into the environment through dissolution and volatilization processes during transportation, storage and production (Magdouli et al., 2013; Sirivithayapakorn and Limtrakul, 2008). The potential release of DEHP may attributes to its applications in PPCPs, paints, medical devices and laboratory equipment (Chen et al., 2008; Franco et al., 2011; Koniecki et al., 2011). Its intensive applications as plasticizer have been also reported in non-polyvinyl chloride materials, such as natural and synthetic, rubber, polyvinyl butyral, chlorinated rubber, ethyl cellulose and nitrocellulose (NTP, 2011; SPMP, 2001; Teil et al., 2007). Globally, the annual production of DEHP is reported as more than 2 million tons (Chan et al., 2007; Koch et al., 2003b). For example, EU produces approximately 1 million tons of phthalates each year, with $50 \%$ DEHP as a dominant compound (Lin et al., 2009). Similarly, $60 \%$ phthalates production with the annual potential of 250, 000 tons is attributed to DEHP in Germany and 100,000 tons of DEHP-laden waste is released into the environment (Koch et al., 2003a; 2003b).

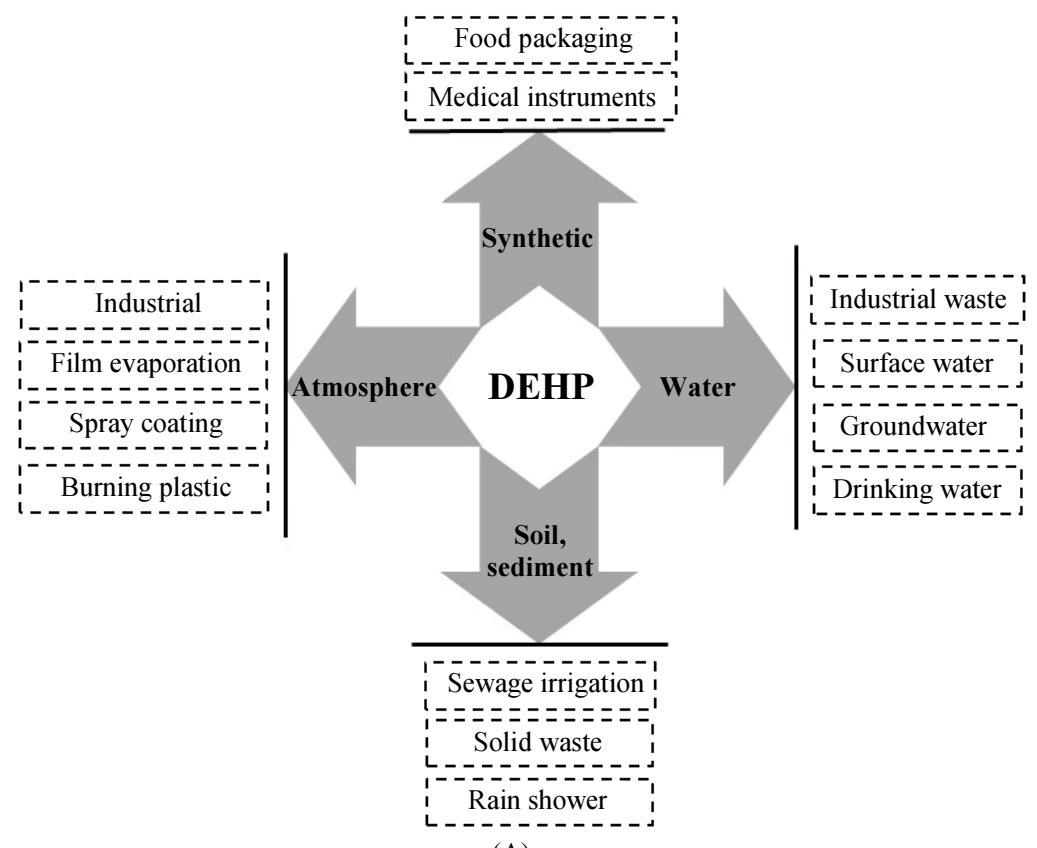

(A) 


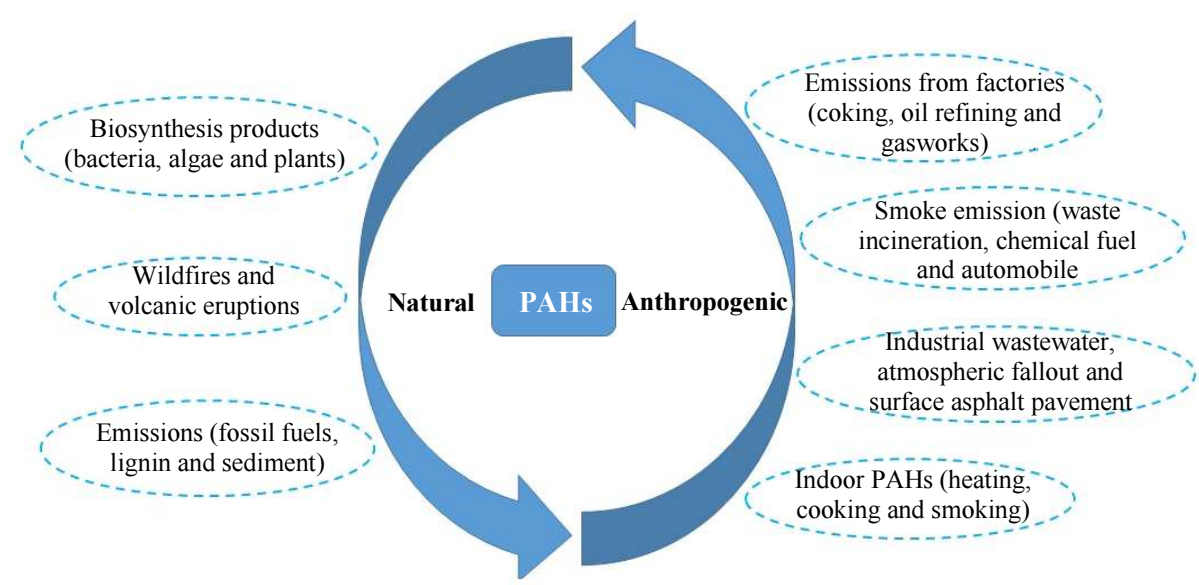

(B)

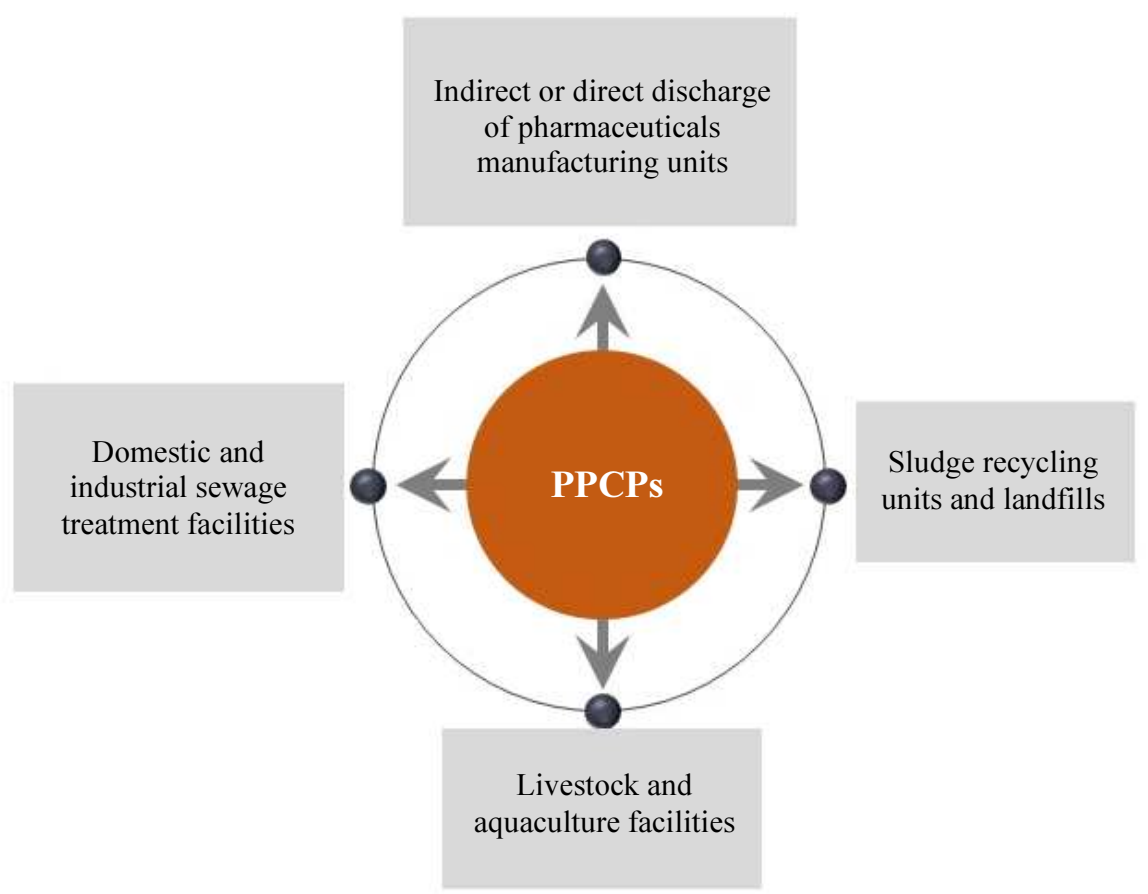

(C)

Fig. 1: Potential sources of DEHP (A), PAHs (B) and PPCPs (C)

PAHs comprise of both the natural and anthropogenic sources (Fig. 1B). The natural sources of PAHs include carbonization, hydrothermal process, forest fire and volcanic eruption and anthropogenic sources comprise incomplete combustion of fossil fuels, pyrolysis of hydrocarbon materials, the release of oil and petroleum products (Lee et al. 1981; Ravindra et al., 2008). The anthropogenic sources of PAHs are further classified as pyrogenic (combustion) and petrogenic (noncombustion). PAHs have unique characteristics, such as ubiquitous nature, resistance to degradation and longrange transportations through environmental media (Turner et al., 2014; Yunker et al., 2002). The surface water contamination of PAHs is usually linked to the industrial emissions through atmospheric deposition and industrial effluents (Han and Currell, 2016).

Regarding the sources of PPCPs, domestic wastewater and hospital effluents are the significant contributing sources for their presence in surface waters (Fig. 1C). Pharmaceuticals are not fully metabolized in the human body, therefore, the parent compound and associated metabolites excrete and make their way to Wastewater Treatment Plants (WWTPs) (Ribeiro et al., 2016). Agriculture run-off is also reported as a significant source of organic pollutants (Moore et al., 2002). Further, the farming of livestock has been also 
reported to produce wastewater containing veterinary drugs that are excreted by animals (Moore et al., 2002). Sewage treatment facilities and leaching of dumping sites and environmental disaster are also the other possible sources PPCPs (Ribeiro et al., 2015). Although many of the basic water pollutants efficiently remove via WWTPs, the removal of organic pollutants especially pharmaceutical is still a dilemma that has attracted the significant attention of the scientific community, recently (Fattakassinos et al., 2015; Luo et al., 2014). The conventional WWTPs are not usually designed to remove organic pollutants, therefore, the introduction of such pollutants to waterways is inevitable and a serious threat for ecological and human health (Barbosa et al., $2016 \mathrm{~b}$ ). Tracking the point and non-point sources of organic pollutants is of immense importance to control the emissions at the source level, albeit the studies are still scarce related to specific source inventories for emerging organic contaminants.

\section{Occurrence and Spatial Distribution of DEHP, PAHs and PPCPs in the Surface Water}

\section{DEHP}

Due to the ubiquitous nature of organic pollutants, they have been detected in most of the waterways worldwide. The compositional pattern of organic compounds greatly varies according to different spatial and temporal scenarios, albeit their occurrence in the surface waters has been reported substantially higher than that of groundwater and drinking water and only a few contaminants are regulated till now (Benotti and Brownawell, 2009; Caliman and Gavrilescu, 2009; NACWA, 2012). In 2007, the European WFD has devised the permissible limit of DEHP in the surface water as 1.3 $\mu \mathrm{g} \mathrm{L}^{-1}$ (Magdouli et al., 2013). Previously, alarming levels of DEHP as high as $13050 \mu \mathrm{g} \mathrm{L}^{-1}$ in the Liao River (China), $2306 \mu \mathrm{g} \mathrm{L}{ }^{-1}$ in the Eastern Cape River (South Africa), $1390 \mu \mathrm{g} \mathrm{L}^{-1}$ in Kunming Lake (China), $1299 \mu \mathrm{g} \mathrm{L}^{-1}$ in the Xuanwu Lake (China), $380 \mu \mathrm{g} \mathrm{L}^{-1}$ in the Kulis River (South Africa) and $97.87 \mu \mathrm{g} \mathrm{L}^{-1}$ in Furu River (Japan), have been reported in different freshwater systems (An and Jin, 2000; Fatoki and Noma, 2002; Fromme et al., 2002; Olujimi et al., 2012; Shen et al., 2010; Yu et al., 2011a) (Table S1). Further, the elevated but relatively lower levels of DEHP have been also reported in other riverine systems in China, such as $54.73 \mu \mathrm{g} \mathrm{L}^{-1}$ in the Wuhan section, Yangtze River, $34.20 \mu \mathrm{g} \mathrm{L}^{-1}$ in the Hun River and $24 \mu \mathrm{g} \mathrm{L}^{-1}$ in the Yellow River (Li et al., 2015a; Sha et al., 2006; Wang et al., 2008). However, DEHP level was less in the rivers of EU countries, e.g., $6.44 \mu \mathrm{g}$ $\mathrm{L}^{-1}$ in the Seine River estuary (France), $1.70 \mu \mathrm{g} \mathrm{L}^{-1}$ in the River of France and $<0.44 \mu \mathrm{g} \mathrm{L}^{-1}$ in North-West River (Spain) (Dargnat et al., 2009; Regueiro et al., 2008; Tran et al., 2015). Similarly, the lower DEHP levels have been reported at $<1.10 \mu \mathrm{g} \mathrm{L}^{-1}$ in the Bang Pa-kong and other River (Thailand), $1.4 \mu \mathrm{g} \mathrm{\textrm {L } ^ { - 1 }}$ in the Kaveri River (India), $0.38 \mu \mathrm{g} \mathrm{L}^{-1}$ in the Selangor River (Malaysia) (Santhi and Mustafa, 2013; Selvaraj et al., 2015; Sirivithayapakorn and Thuyviang, 2010).

The main sources of DEHP in the water bodies can be attributed to the discharge of the untreated industrial wastewater, cosmetics, lubricants and adhesive wastes containing traces of plastics (Chen et al., 2012). The spatial distribution of DEHP levels $(\mu \mathrm{g} / \mathrm{L})$ in surface waters worldwide revealed elevated levels in Asian and African regions (Fig. 2A). For instance, the levels of DEHP $(\mu \mathrm{g} / \mathrm{L})$ were reported highest in China; Liao River, Anshan (13050 $\mu \mathrm{g} \mathrm{L}^{-1}$ ) followed by Kunming Lake $\left(1390 \mu \mathrm{g} \mathrm{L}^{-1}\right)$ and Yangtze river $\left(1299 \mu \mathrm{g} \mathrm{L}^{-1}\right)$ (Yu et al., 2011a; He et al., 2011a; An and Jin, 2000). Overall, the DEHP levels from the world indicated the highest loads in Asia followed by Africa, Europe and North America (Fatoki and Noma, 2002; Dargnat et al., 2009; Fromme et al., 2002; Yu et al., 2011a). Perhaps the main reason behind the rapid industrialization in the Asian region, especially in China. It is reported that in China, over one million tons of phthalates (including DEHP) is consumed per year, accounting for one-fifth of the global consumption (Liu et al., 2014).

\section{PAHs}

Regarding the environmental occurrence of PAHs, the elevated levels have been reported in the rivers those stretch through densely populated regions in China, such as Yangtze River (Chongqing and Shanghai sections), Haihe River (Tianjin), Taihu Lake (Beijing), Tonghui River (Beijing) (Han and Currell 2016). Some of the previous studies are summarized in Table S2. The maximum values of PAHs were reported as high as 43,226 ng $\mathrm{L}^{-1}$ in the Lanzhou section of the Yellow River (Li et al., 2006), 35,210 $\mathrm{ng} \mathrm{L}^{-1}$ in the Tianjin section of the Haihe River (Cao et al., 2005), $96,210 \mathrm{ng} \mathrm{L}^{-1}$ in the Hangzhou River (Zhu et al., 2004), 26,920 ng $\mathrm{L}^{-1}$ in the Jiulong River Estuary (Maskaoui et al., 2002), 34,000 $\mathrm{ng} \mathrm{L}^{-1}$ in the Taihu Lake (Guo and Fang, 2012), 474,000 ng L ${ }^{-1}$ in the Minjiang River Estuary (Zhang et al., 2004) and 34,338 $\mathrm{ng} \mathrm{L}^{-1}$ in Humen section of the Pearl River (Yang et al., 2004). These reported values in different riverine systems of China are substantially higher than that of PAHs permissible values of $100 \mathrm{ng} \mathrm{L}^{-1}$ (WFD 98/83/EC)

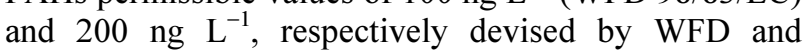
USEPA (Han and Currell, 2016). Similarly, the alarming levels of PAHs have been reported in the Gomti, River, India (60-84,210 $\mathrm{ng} \mathrm{L}^{-1}$ ) (Malik et al., 2011). These high levels of PAHs can induce alarming ecological risk and acute toxicity to aquatic species. In comparison, the rivers from USA, Europe and Australia have been reported with lower PAHs levels than those in Asia, as reviewed previously (Han and Currell 2016). For example, PAHs concentrations 
were detected at 12.4 to $2321 \mathrm{ng} \mathrm{L}^{-1}$ in the Sarno River, Italy (Montuori and Triassi 2012), 4-36 ng L ${ }^{-1}$ in the Seine River, France (Fernandes et al. 1997),
5.1-12 $\mathrm{ng} \mathrm{L}^{-1}$ in the Brisbane River, Australia (Shaw et al., 2004) and $12-434 \mathrm{ng} \mathrm{L}^{-1}$ in the lower Mississippi River, USA (Mitra and Bianchi 2003).
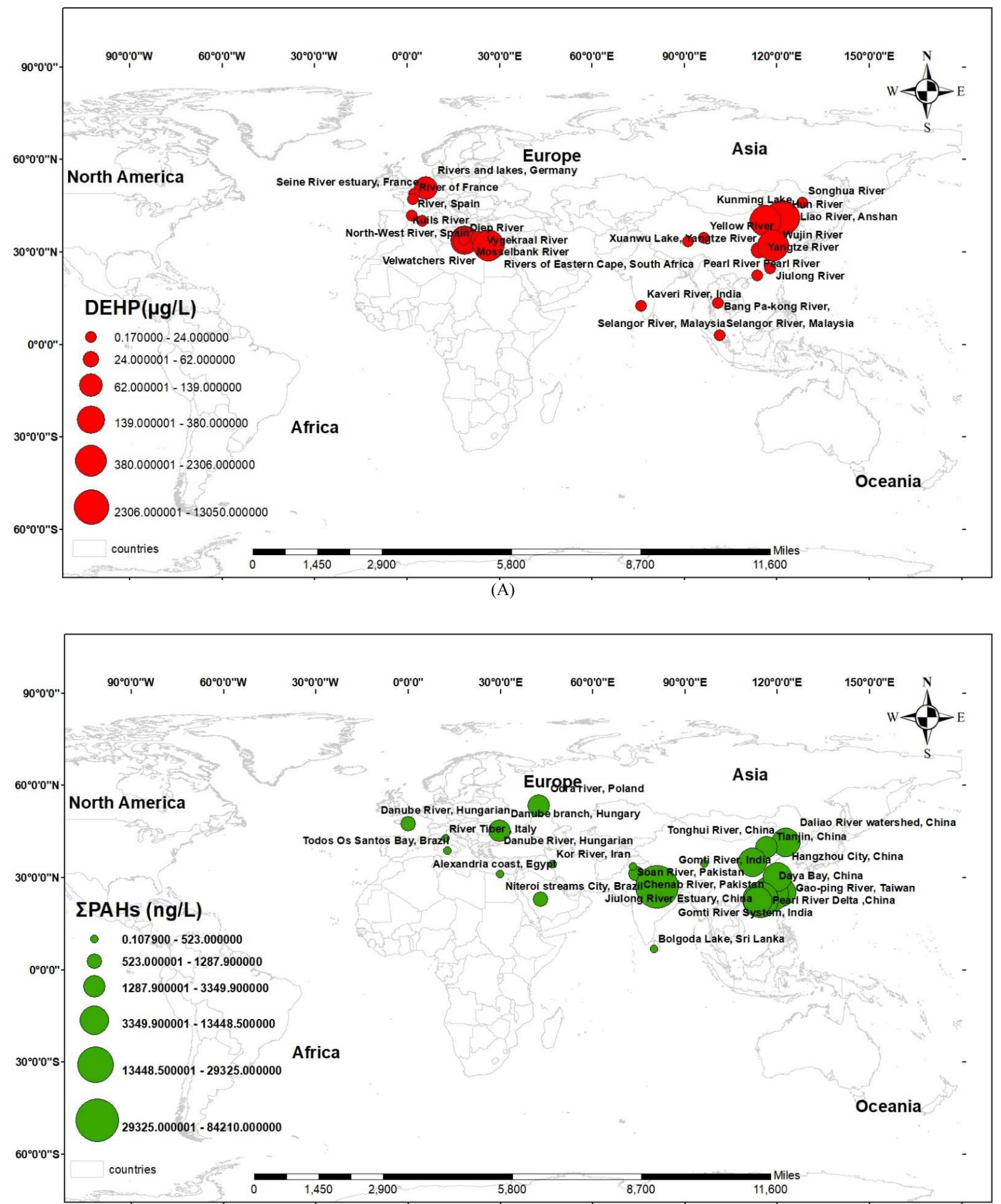

(B)

Fig. 2: Spatial distribution of DEHP $(\mu \mathrm{g} / \mathrm{L})(\mathrm{A})$ and $\Sigma$ PAHs $(\mathrm{ng} / \mathrm{L})(\mathrm{B})$ in the surface waters 
The major route of PAHs entering in the water bodies is the direct release of the untreated domestic waste water, industrial discharges, petroleum spills and through atmospheric deposition (Hamid et al., 2016). Due to the hydrophobic nature of PAHs, in the aquatic environment it rapidly tends to become associated with the particulate matter and deposited in the sediments (Srinivasa et al., 2005). Globally, a comparative spatial distribution analysis revealed that the environmental levels of PAHs in surface water were in the following order: India $>$ China $>$ Poland $>$ Taiwan $>$ Pakistan (Fig. 2B). $\sum$ PAHs concentration levels ranged between $0.10 \mathrm{ng} \mathrm{L}^{-1}$ (Todos os Santos Bay, Brazil) and $75570 \mathrm{ng} \mathrm{L}^{-1}$ (Gomti river system, India) (Jose celino et al., 2012). Industrialization and urbanization have escalated rapidly during the last few decades in India. The massive biomass burning to meet fuel requirements aggravates the situation (Malik et al., 2004). In contrast with, China is considered to the $3^{\text {rd }}$ major PAHs emitter country because of large coal production (Zhang and Tao, 2009). Worldwide, the PAHs pollution was in the order of Asia $>$ Africa $>$ Europe respectively.

\section{PPCPS}

Wastewater from domestic and industrial WWTPs is mainly responsible for the occurrence of PPCPs in the aquatic environment due to the poor removal efficiency of conventional treatment plants for PPCPs (Deblonde et al., 2011; Ke et al., 2015). Further, improper dumping of unused and expired pharmaceuticals also directly contribute to the abundance of pharmaceuticals' in the waterways, which are basically originated from toilet sinks or solid waste (Aydin and Talinli, 2013; Barbosa et al., 2016a; Gorito et al., 2017). Aquatic environment has been reported with the contamination of more than 80 PPCPs and several metabolites (Heberer, 2002; Jelic et al., 2011). The basic reasons behind the wide existence of PPCPs are the ease of excess and product proliferation, which significantly contribute to the invasion of these xenobiotics to the natural and built environments (NACWA, 2012). However, the detection of PPCPs in the aquatic environment is not new, as they have gained considerable attention during last decade due to their alarming levels, diverse and growing ecotoxicological risks in the environment (Wilkinson et al., 2017). For instance, Jones et al. (2002) modelled the concentrations of the frequently used 25 pharmaceuticals including antiepileptic and analgesic drugs in the aquatic environment of the U.K and conservative estimates revealed the concentration was exceeding $1 \mathrm{ng} \mathrm{L^{-1 }}$ for most of the pharmaceuticals. Pharmaceuticals used for the treatment of different disease, such as antidepressant, asthma, central nervous system stimulus and cholesterolregulating medication are also detected in the surface waters of U.S. (CDC, 2010). In 2000, U.S. Geological Survey conducted a comprehensive study on 95 most common PPCPs in 136 different streams and rivers running through the urban centers of U.S. The findings of this survey generally revealed low levels of PPCPs in surface waters and even lower than that of drinking water quality standards. However, the detection frequency of PPCPs was as high as 82 out of 95 total PPCPs (Buxton and Kolpin, 2005; Kolpin et al., 2002). Further, the physiologically active compounds were also found in the surface waters that were known to be endocrine disruptors. In addition, the median number for PPCPs mixture found in an individual river was 7 and the maximum number was 38 , implying the combined or co-existence of these compounds (Kolpin et al., 2002). PPCPs can be further classified into several categories and this review included two of them, i.e. PCPs and NSAIDs. The comparative highest environmental levels of NSAIDs and PCPs are listed in Table S3 and S4. NSAIDs, e.g. IBU, NAP and DIC are easily accessible, commonly prescribed and highly consumed drugs, worldwide. Recently, the environmental concentration of NSAIDs has been reported to be constant over the years in specific regions. The median levels of IBU and NAP have been measured at 200 and $550 \mathrm{ng} \mathrm{L}^{-1}$ in the surface water samples from canals of Canada and New Jersey, respectively (Li, 2014). Further, the concentration of PCPs, such as synthetic musks, e.g., musk xylene (MX) and musk ketone (MK), typically ranged between 150$16700 \mathrm{ng} \mathrm{L}^{-1}$ and these PCPs have widely used in cosmetics, lotions, perfumes, soaps and deodorants (Lee et al., 2010; Roosens et al., 2007).

In China, the pharmaceutical fraction of PPCPs revealed wide occurrence in the major riverine systems, such as Yangtze River (Zhou et al., 2011), Pearl River (Peng et al., 2008), Hai River, Liao River and Yellow River (Wang et al., 2010). Due to the dilution effect of rainfall, the median concentrations and detection frequency were reported to be lower during the high flow seasons than that of low flow seasons (Peng et al., 2008). Further, the sampling sites near metropolis appeared more contaminated with pharmaceuticals because of the direct disposal of pharmaceuticals to the surface waters via untreated wastewater from WWTPs and domestic sources (Wang et al., 2010; Yu et al., 2011b). Similarly, the elevated levels of pharmaceuticals were reported in the Rivers from Brazil (Stumpf et al. 1999), Japan (Nakada et al., 2008), Korea (Kim et al., 2007), U.S. (Kolpin et al., 2004) and U.K. (Thomas and Hilton, 2004). Comparatively, the Vantaa River in Finland appeared with low concentrations of pharmaceuticals (Vieno et al., 2007). For PCPs, the elevated 
concentration was reported in the urban rivers of Pearl Delta region, Guangzhou. PCPs, such as Methylparaben (MP) and Propylparaben (PP), Triclosan (TCS) and Triclocarban (TCC) were detected with high frequency (Liu and Wong 2013; Peng et al., 2008; Zhao et al., 2009). Similarly, TCS and TCC were also reported in the Liao River, Hai River, Yellow River, Pearl River and
Dongjiang River in China (Zhao et al., 2013). The Shanghai section of the Yangtze River was also reported with elevated concentrations and detection frequency of synthetic musks (Zhang et al., 2008). The extremely high concentration of TCS was reported in the Tamiraparani River, Kaveri River and Vellar River in India (Ramaswamy et al., 2011).

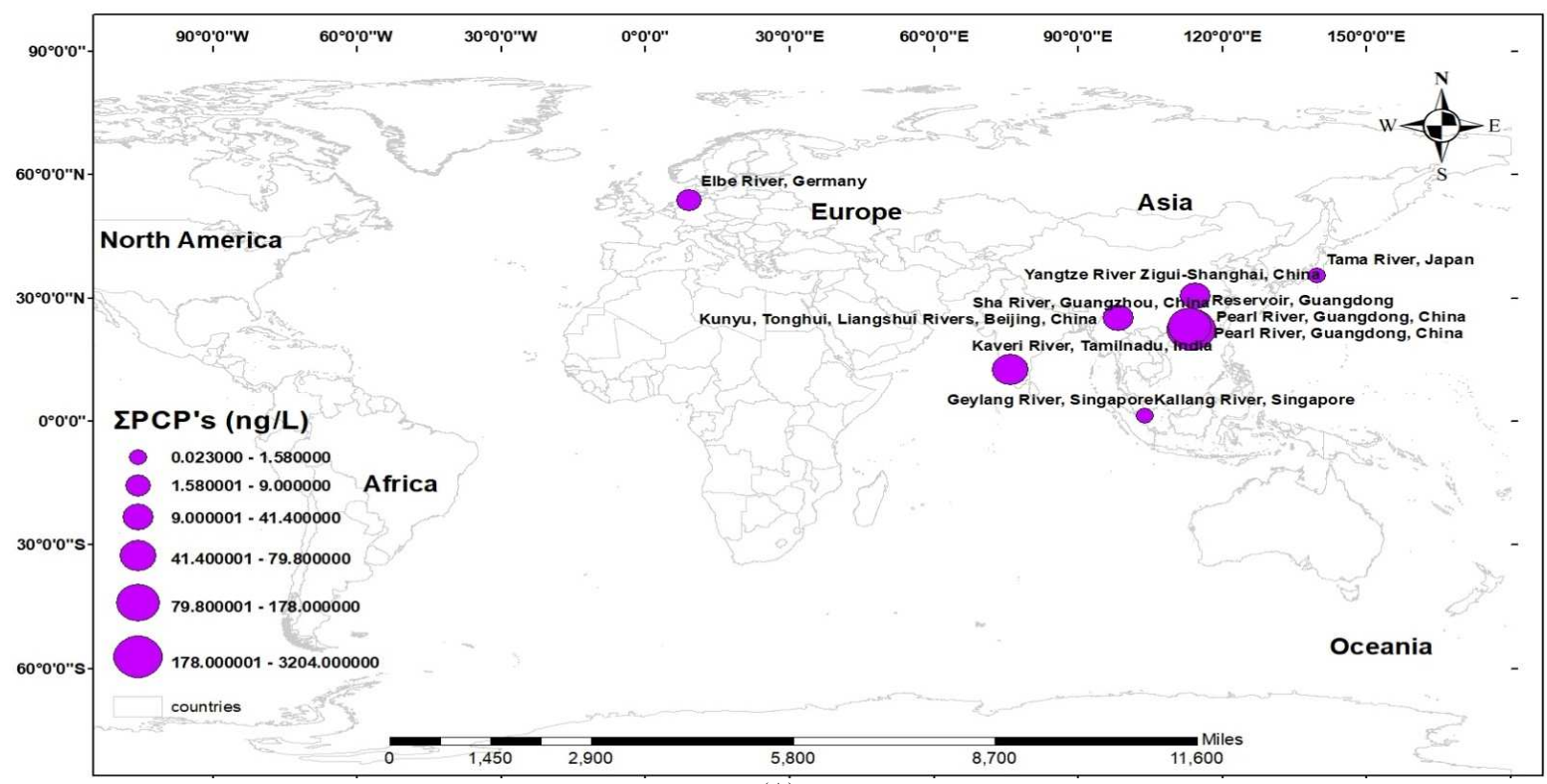

(A)

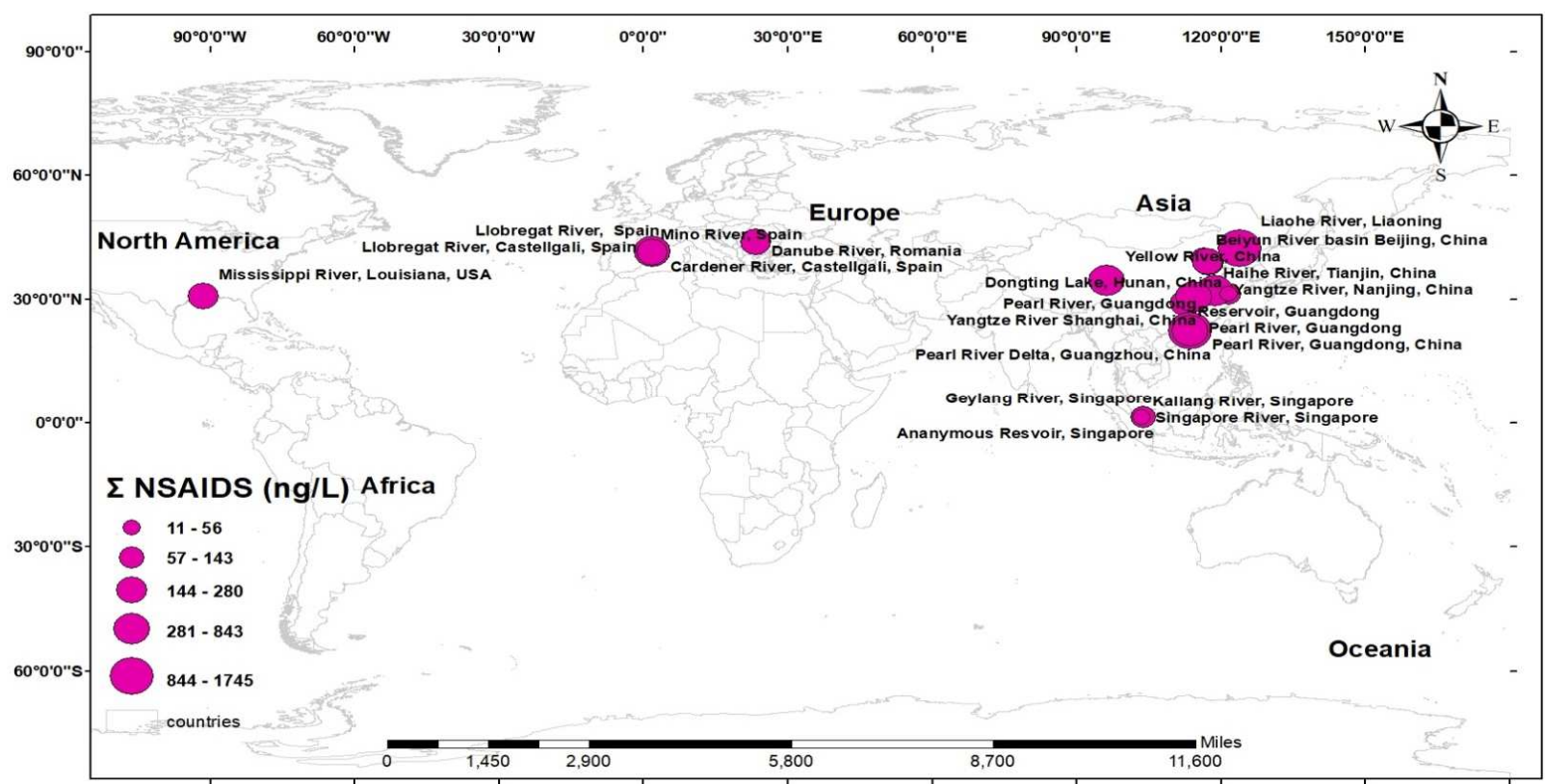

(B)

Fig. 3: Spatial distribution of $\Sigma$ PPCPs levels (ng/L) in terms of Personal Care Products (PCPs) (A) and Non-Steroid Anti-Inflammatory Drugs (NSAIDs) (B) inthe surface waters worldwide. The maximal reported concentrations of DEHP in the surface waters of different riverine systems are used to develop this map. $\Sigma$ PCPs included Methylparaben (MP), Propylparaben (PP) and Musk Xylene (MX) and $\Sigma$ NSAIDs included Naproxen (NAP), Ibuprofen (IBU) and Diclofenac (DIC) 
There are few limited studies reported in surface water of PCPs, worldwide. The spatial distribution analysis of the reported PCPs in the surface waters clearly showed that the rivers in Asia are appeared to be more polluted with PCP's than the rivers in Europe and Africa (Fig. 3A). In China, the Liaohe River, Liaoning was found the maximum levels reported $\left(123.875 \mathrm{ng} \mathrm{L}^{-1}\right)$, followed by the Huangpu River, Shanghai (121.5 $\left.\mathrm{ng} \mathrm{L}^{-1}\right)$ and the Yangtze River, Nanjing section, (118.73 $\mathrm{ng} \mathrm{L}^{-1}$ ) (Liu et al., 2015a; Gao et al., 2016; Yang et al., 2011). NSAIDs enter in the aquatic environment is through the untreated waste-water coming from the pharmaceutical industries. However, the residues contain trace levels of NSAIDs. The spatial distribution of NSAIDs showed that the highest concentration was found in the Liaohe River, Liaoning (1003.7 $\mathrm{ng} \mathrm{L}^{-1}$ ) followed by Pearl River, Guangdong (1475 $\mathrm{ng} \mathrm{L}^{-1}$ ) and Cardener River, Castellgali, Spain (484 ng L ${ }^{-1}$ ). (Liu et al., 2015a; 2015b; Chitescu et al., 2015) (Fig. 3B). Limited studies are available for NSAIDS creates a gap and difficult to define the global distribution pattern. Therefore, comprehensive quantification evaluation is required to assess the toxicity in the aquatic environment.

\section{Ecological risks of PAHs, DEHP and PPCPs}

The presence of pollutants in the aquatic environment has been reported to cause ecotoxicological risks, which is yet elusive for several organic contaminants in many surface waters resources and hotspot locations, worldwide (Gorito et al., 2017). The lower concentration of organic pollutants may not capable of inducing the acute toxic effects, albeit chronic exposure can cause adverse impacts that are more difficult to investigate (Tijani et al., 2016). Contrarily, previous studies revealed that even the low concentrations of organic pollutants have potentials to impair biological functions in aquatic species. In addition, the bioaccumulation of organic pollutants in the aquatic species can also cause adverse impacts by disturbing immune system and endocrine disruption, which can lead to the neurological, reproductive and developmental abnormalities (UNESCO, 2015).

Several methods have been devised till now to quantify the ecological risks of organic pollutants to the aquatic species. The most common method is to calculate Risk Quotients (RQs) based on spatial exposure by using Measured Environmental Concentrations (MECs) and compared them with the Predicted No-Effect Concentrations (PNECs) for acute exposure or chronic exposures (Slobodnik et al., 2012; Tousova et al., 2017). The RQs were calculated as the ratio between the maximum MECs (95\%) and the lowest PNECs, which actually highlight the levels ecological risks associated to a specific class of pollutants (Pc et al., 2011). Further, the ecological risks are also calculated by using the guidelines devised by EMA. In which the RQs are extracted as the ratio between Predicted Environmental Concentrations (PECs) and PNECs (EMA, 2006). For a better understanding, the ecological risks are usually classified on the basis of RQs, such as the values $<0.1$ indicating the low-level risk, 0.1-1 meaning the mediumlevel risks and the values $>1$ indicating the high-level risks (Hernando et al., 2006; Paiga et al., 2016).

The lack of ecological risk inventory for acute and chronic adverse effects of organic pollutants in the aquatic environment demands precautionary measures (Deblonde et al., 2011; Gavrilescu et al., 2015). Ecological risk/hazard assessment is to investigate the changes in aquatic species as result of exposure to environmental stressors, such as organic contaminants (Ogbeide et al., 2015). The tracking of ecological risks of organic pollutants is of critical importance to regulate the PSs and CECs and the adverse effects may accumulate continuously to cause irreversible molecular damages to the aquatic ecosystems (Jjemba, 2006). Another alarming concern related to ecological risk is the synergistic interactions of organic pollutants that can cause unexpected adverse impacts on the aquatic species (Aydin and Talinli, 2013; Dai et al., 2015).

We also calculated the ecological risks of DEHP, PAHs and PPCPs in terms of RQs using MECs and PNECs reported in the surface waters, worldwide. The spatial distribution of RQs for DEHP indicated that the highest risks were observed in terms of RQs in the rivers of China, such as Liao River, Anshan (371.7) followed by Kunming Lake (39.5) and Yangtze River (37) than the river present in South Africa (65.6) (Fig $4 a)$. DEHP is the most ubiquitous chemical phthalate in the aquatic environment with the ability to pose high level risks in the ecological environment. Based on the calculated high level risks found in China's surface water, necessary mitigation actions should be taken by the government agencies to overcome the associated effects (Chen et al., 2012). Globally, for the estimation of the ecological risk caused by PAH's in surface waters, the results of spatial distribution showed that RQs order was in accordance with the PAHs levels i.e. India (311) > China (110) > Poland $>$ (38.5) Taiwan (17.5) $>$ Pakistan (5.3) respectively. While lower level risk reported inthe rivers of Brazil, Italy and Europe (Fig 4b).

In comparison with the risk calculated for PAHs and DEHP, PCP's showed relatively low levels. The lowlevel RQs range (0.001-0.2) were extracted for PCPs reported in the surface waters of different rivers worldwide (Liu and Wong, 2013; Yu et al., 2011b) (Fig 5a). Likewise, for NSAIDs, the calculated RQs showed negligible risk (0.001-0.2) (Fig 5b). Contrarily, some of the previous studies revealed alarming ecological risks in the surface water resources associated to NSAIDs and other pharmaceuticals (Nie et al., 2015; Xu et al., 2013). 


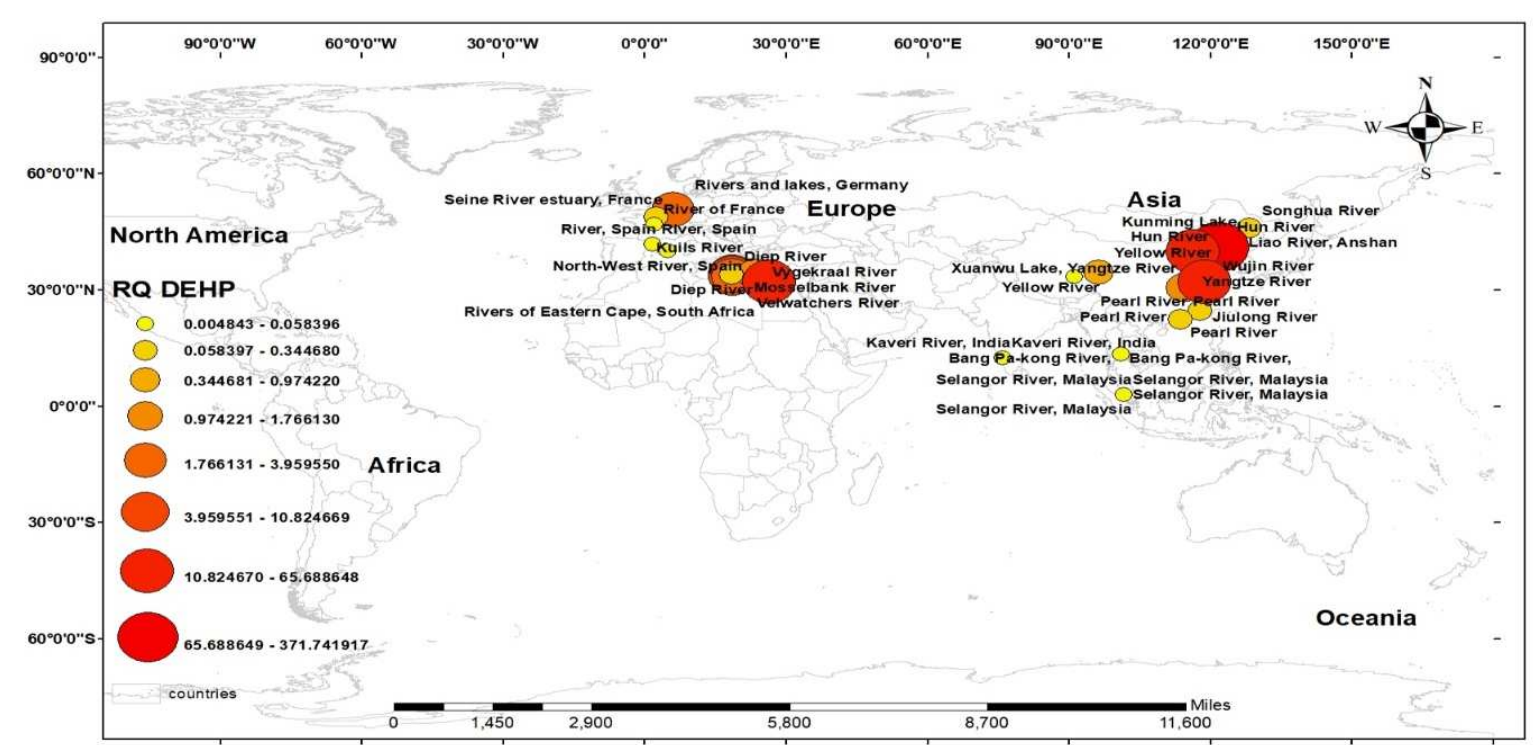

(A)

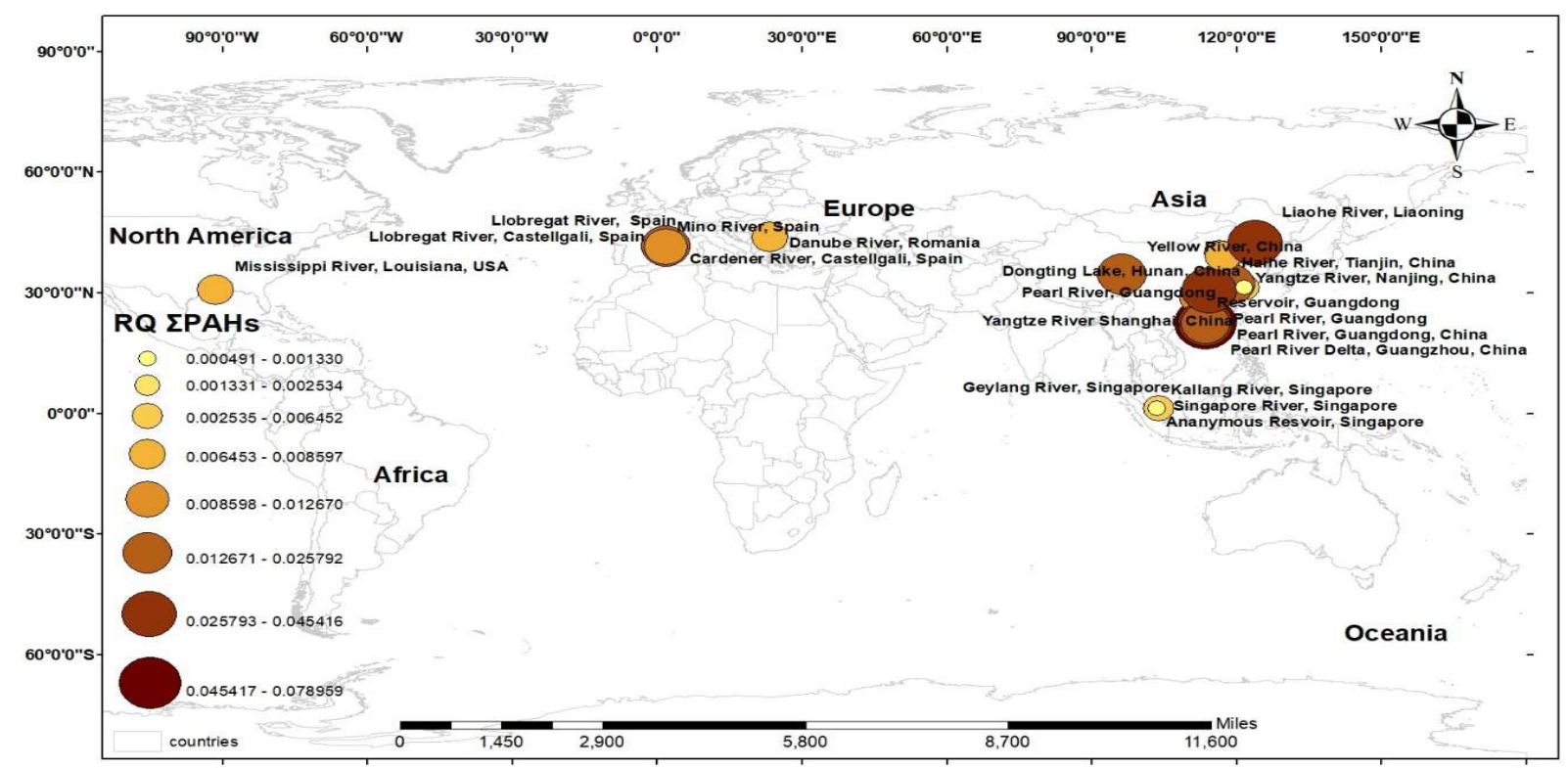

(B)

Fig. 4: Spatial distribution of ecological risks in terms of risk quotients (RQ) of DEHP (A) and $\Sigma$ PAHs (B) observed in the surface waters worldwide. RQs were calculated as a ratio of Measured Environmental Concentrations (MECs) and Predicted no Effect Concentrations (PNECs) of DEHP and PAHs reported previously. MECs used in this study for ecological risk assessment of DEHP and PAHs are given in Table S1 and S2. PNECs for DEHP and PAHs were respectively extracted from Liu et al. (2016 and Cao et al., 2005)

Liu et al. (2016) performed ERA of DEHP in surface waters of China and found that DEHP caused elevated risks to the reproduction and other biochemical functions in aquatic species. Yan et al. reported that 3-ring and 4ring PAHs induced higher ecological risk than 2-ring, 5ring and 6-ring PAHs based on their corresponding environmental levels in Hai River basin China (Jia et al.,
2016). A study from Denmark evaluated the ecological risk of 25 commonly used pharmaceuticals in the aquatic environment and RQs higher than 1 were reported for IBU, paracetamol and acetylsalicylic acid (Stuerlauridsen et al., 2000). Similarly, the RQs of mefenamic acid, oxytetracycline and amoxicillin in the Rivers of U.K. were also higher than 1 (Jones et al., 
2002). Another comprehensive study from France investigated 120 pharmaceuticals and their metabolites in the aquatic environment and 49 pharmaceuticals and 14 metabolites needed immediate control on the basis of their bio-chemical properties and PECs (Besse and Garric, 2008). A prioritization approach based study on 200 drugs was conducted in the U.S. that highlighted montelukast sodium and levothyroxine with the highest scores (Dong et al., 2013). Similarly, a ranking based study was performed on 39 pharmaceuticals in China, which revealed DIC and IBU with elevated concerns among investigated pharmaceuticals (Sui et al., 2012). Further, NSAIDs and lipid-lowering drugs were respectively revealed $100 \%$ and $71 \%$ as priority drugs, while for antibiotics it was only $32 \%$. This study concluded that NSAIDs posed the highest ecological risks in aquatic systems in China (Sui et al., 2012). Similarly, the pharmaceuticals, such as amoxicillin, sulfasalazine, trimethoprim, oxytetracycline and erythromycin, also showed elevated ecological risks (RQs values $>1$ ) in different aquatic environments in China (Chen et al., 2015).

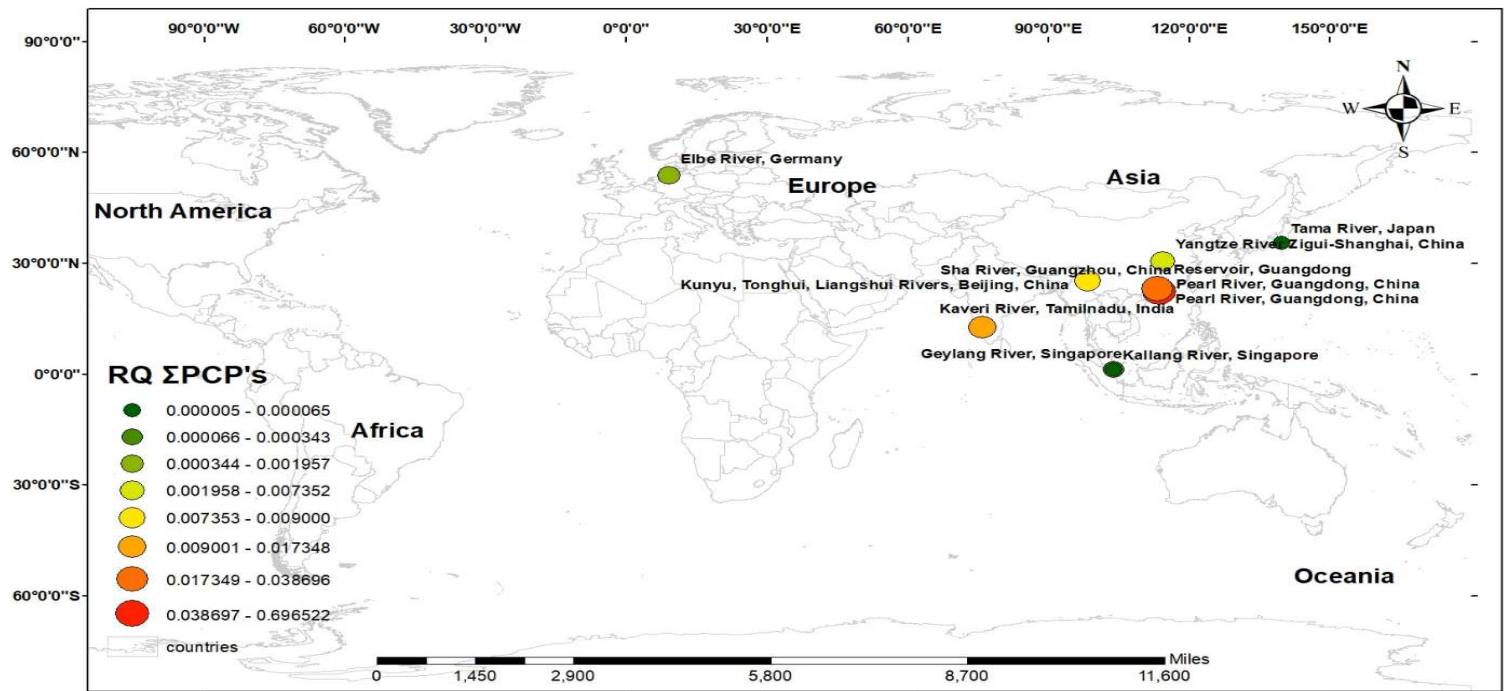

(A)

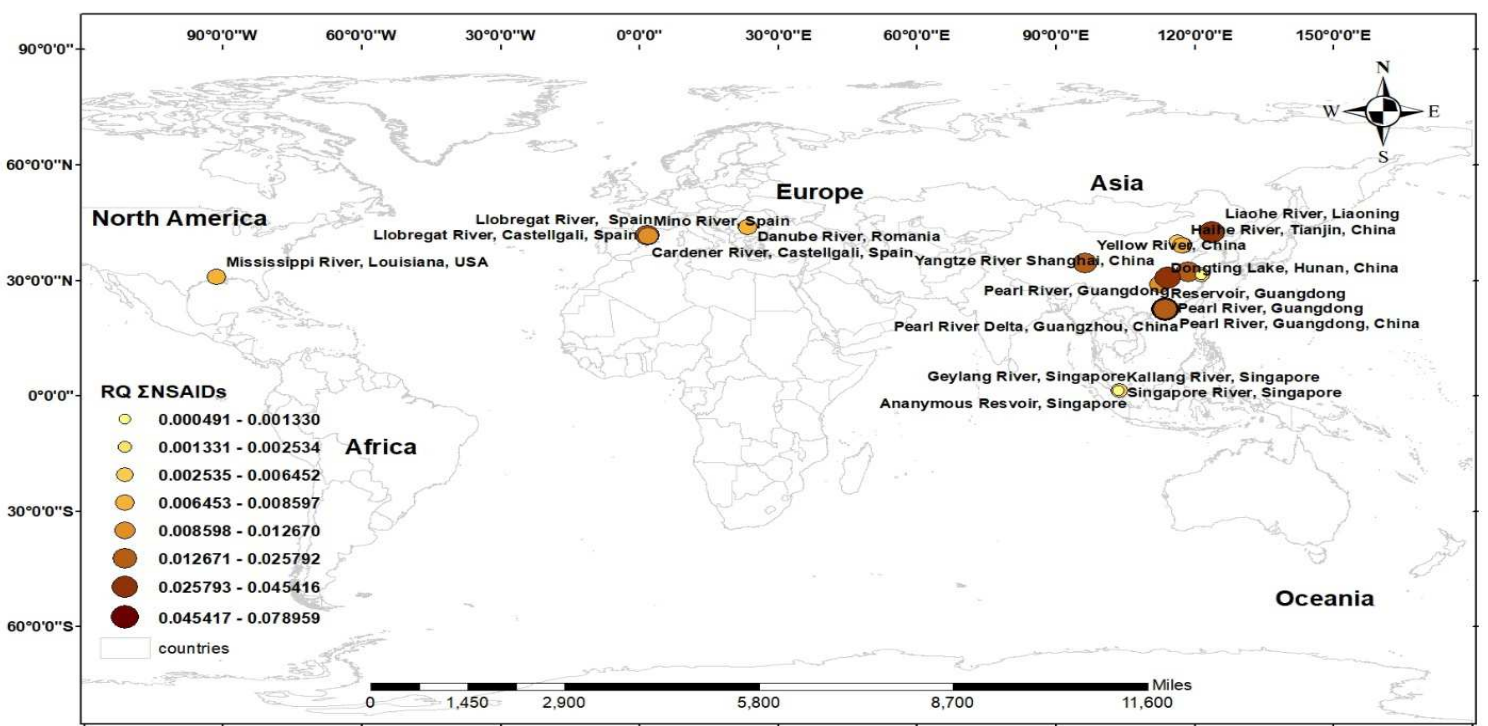

(B)

Fig. 5: Spatial distribution of ecological risks in terms of Risk Quotients (RQ) of $\Sigma$ PCPs (A) and $\Sigma$ NSAIDs (B) observed in the surface waters worldwide. RQs were calculated as a ratio of Measured Environmental Concentrations (MECs) and Predicted no Effect Concentrations (PNECs) of $\Sigma$ PCPs and NNSAIDs reported previously. MECs used in this study for ecological risk assessment of $\Sigma$ PCPs and NSAIDs are given in Table S1 and S2. PNECs for PCPPs were extracted by Barbosa et al.

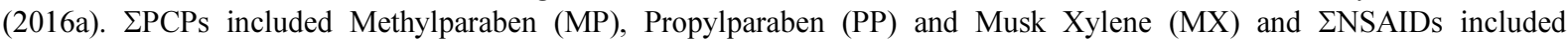
Naproxen (NAP), Ibuprofen (IBU) and Diclofenac (DIC) 


\section{Potential Toxicity of DEHP, PAHs and PPCPs in Vitro/Vivo}

DEHP contamination and associated toxicity caught a considerable amount of attention of the scientific community because of its ubiquitous presence in different environmental compartments (Caldwell, 2012). Although a significant number of previous studies have revealed the potential toxicity of DEHP, the researchers recommended for further in-depth studies to understand conclusive toxic hazards of DEHP after acute and chronic exposures (Magdouli et al., 2013). The general toxicological concerns of DEHP exposure are illustrated in Fig. 6A. DEHP is well known as an endocrine disruptor. It can alter the regulation of reproductive hormones in rat, cause hyperplasia in the Leydig cells, and disturb the systematic physiology (Akingbemi et al., 2004; Sharpe 2001). Further, the speculation exists that the acute toxicity of DEHP is relatively low, whereas chronic exposure can induce drastic effects both in vitro/vivo (Shea, 2003). Further, the inevitable evidence also showed the genotoxicity caused by DEHP through different signaling pathways, such as Peroxisome Proliferator-Activated Receptor (PPAR) and pregnane X receptor (PXR) (Desvergne et al., 2009; Hurst and Waxman, 2004). The PPAR regulates the energy homeostasis and is also responsible for the regulation of hormones involved in the metabolism of lipid, carbohydrates and xenobiotics (Singh and Li, 2011). As a result of PPAR activation after DEHP exposure, other nuclear receptors, such as the Vascular Endothelial Growth Factor A (VEGFA), Estrogen Receptor 1 (ESR1) and Retinoid X Receptor (RXR), are also activated, which play critical roles in hepatocarcinogenesis and atherosclerosis (Botelho et al., 2009; Feige et al., 2010). Further, DEHP promoted the lipid accumulation in HepG2 cells via activating the SREBP-1c and PPAR $\alpha$-signaling pathways (Wang et al., 2016). DEHP can cause apoptosis and down regulate lactotransferrin in MCF-7 and MDA-MB-231 cell lines (Tanay et al., 2014) and induce hepatocellular adenomas in mice (Takashima et al., 2008). Previous studies also showed that DEHP exhibited potential to induce developmental toxicity and disturb the balance of Thyroid Hormones (THs) through activation of HPT axis pathway in zebrafish at Environmentally Relevant Concentrations (ERCs) (Gao et al., 2016; Ma et al., 2017).

The general view of PAHs mediated toxicity is highlighted in Fig. 6B. The toxic impacts of PAHs exposure have been immensely investigated because of their known genotoxic, carcinogenic and mutagenic nature (Kim et al., 2013). Some of PAHs congeners are not classified as the carcinogen, albeit they may induce synergistic toxic impacts (Staal et al., 2007). PAH binary mixtures revealed synergistic effects on cell cycle blockage and apoptosis in HepG2 cells (Staal et al., 2007). The dermal exposure of rats to petroleum products containing high molecular weight (HMW) PAHs can induce developmental toxicity, such as reduced body weights, skeletal malformations and other teratogenic effects (Mackerer 1996). Another study highlighted that the exposure to individual PAHs: naphthalene (Nap), phenanthrene (Phe), Benzo(a)Anthracene (BaA) and benzo(a)pyrene (BaP) altered the molecular markers in the whole blood of rat and these molecular alterations can be used for discriminating different PAHs congeners (Jung et al., 2011).

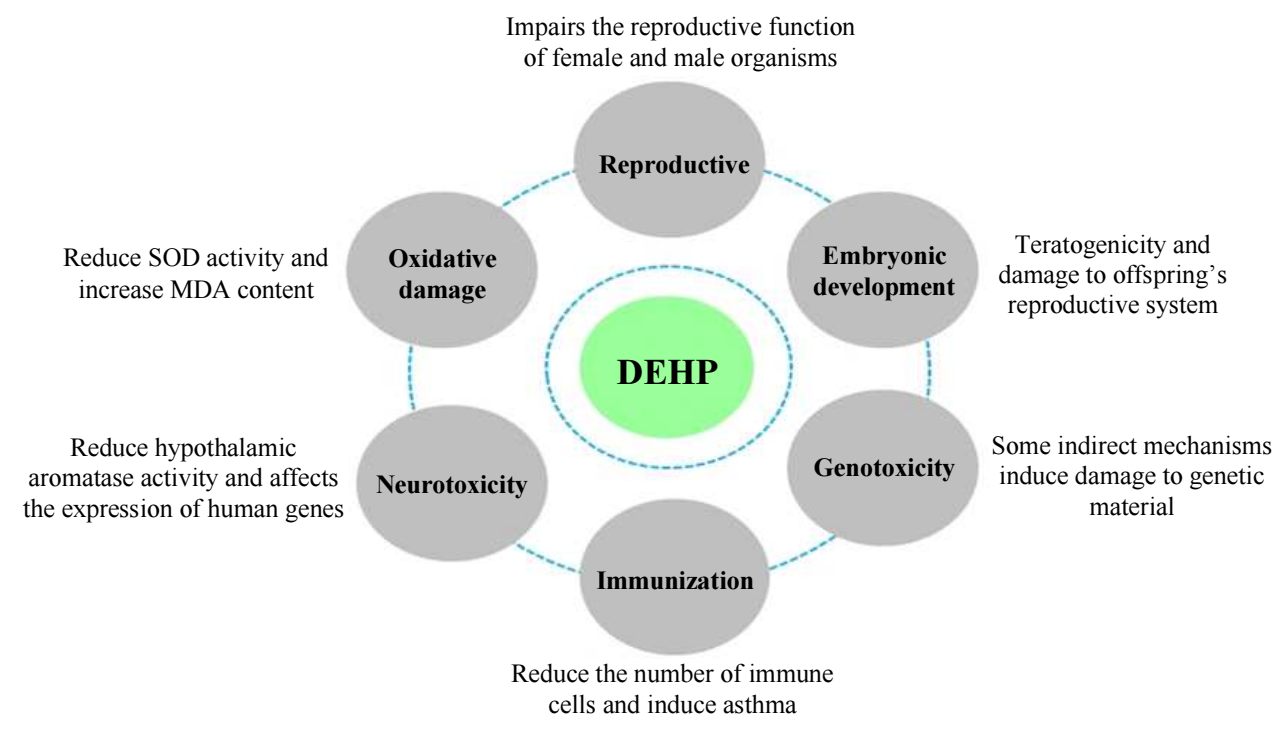

(A) 


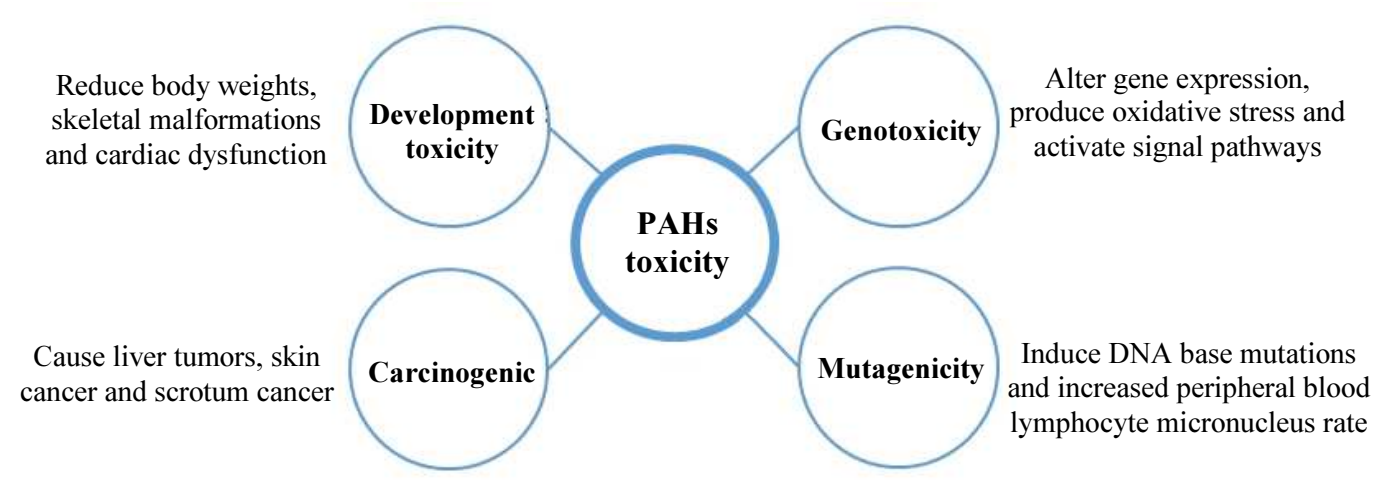

(B)

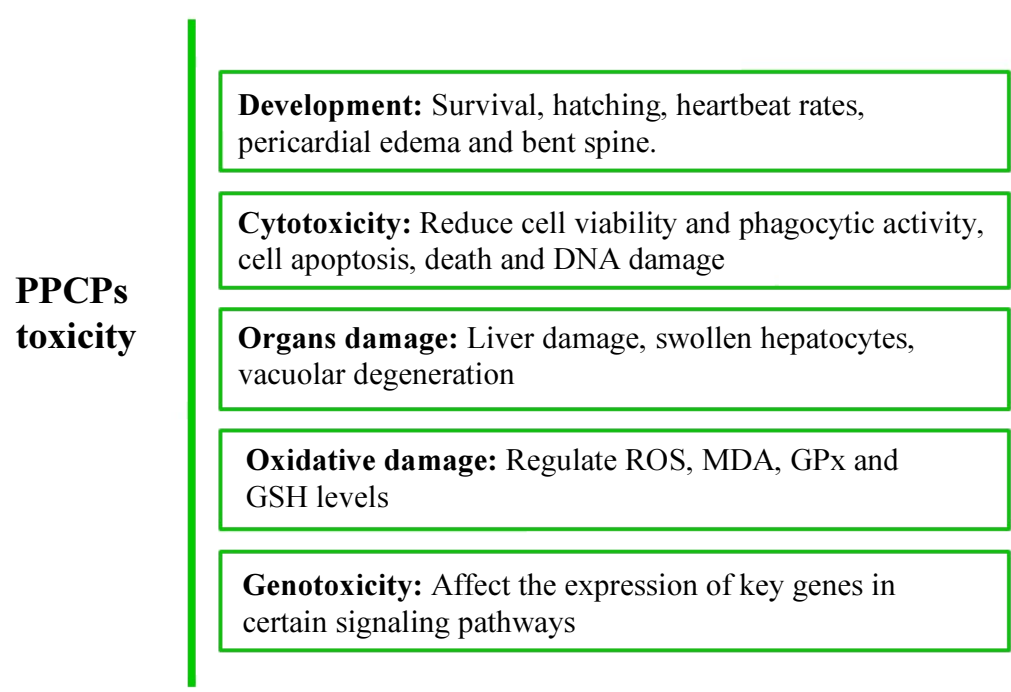

(C)

Fig. 6: Toxicological concerns of DEHP (A), PAHs (B) and PPCPs (C) revealed in different in vitro

Hook et al. (2010) reported that the PAHs exposure altered the genetic expression of cypla3 in the liver of trout fish. Further, the enzymes involved in xenobiotic metabolism and immune systems, such as GSTs, were also significantly altered, which might be an indicator of oxidative stress, PAHs congeners induced genetic toxicity through activation of PPAR and Mitogen-Activated Protein Kinase (MAPK) signaling pathways in liver tissues of exposed rats (Jung et al., 2013). PAHs with similar structures induced comparable levels of genetic alterations, which was ascribed to the same metabolic pathway, such as cytochromes P450 (CYP450) associated oxidation. Structural variations in PAHs can induce diversified developmental abnormalities and skeleton malformations in fish (Huang et al., 2013; Zhang et al., 2012). A transcriptome analysis based study revealed that exposure to $\mathrm{BaA}$ altered the genetic expressions hox and fox in zebrafish and these genes control the skeletal development in zebrafish. The genetic expression of hox was also altered by other PAHs congeners, such as pyrene (Pyr) and benzo[b]fluoracene (BbF) (Goodale et al., 2013; Hawliczek et al., 2012). The pax6 gene that is responsible for the morphogenesis of eye was also found with abnormal expressions after exposure to Phe (Huang et al., 2013). Further, exposure to BaP (a model carcinogen) can induce negative effects on the Sonic Hedgehog ( $\mathrm{SHH}$ ) signaling pathway in rockfish, which also play a crucial role in skeleton development (He et al., 2011a).

PAHs commonly plays an important role through Aryl hydrocarbon Receptor (AhR) pathway and alters the expression levels of CYP450 family enzymes (Staal et al., 2006; Xie et al., 2017). However, the Low Molecular Weight (LMW) PAHs (3- and 4-ring), such as Fluorene (Flu), Acenaphthene (Ace), Acenaphthylene (Acp) and Phe, showed no affinity to AhR (Xu et al., 2015). Although 3- 
ring Phe revealed no AhR activity, its exposure at elevated doses can cause developmental effects on cardiac dysfunction in zebrafish. These studies suggested that AhR pathway may not be the only mode of action associated with PAHs toxic impacts (Incardona et al., 2004). In addition, the exposure to $\mathrm{BaA}, \mathrm{BbF}$ and $\mathrm{BaP}$ also caused AhR mediated cardiac toxicity in fish. Whereas, Benzo[k]Fluoranthene $(\mathrm{BkF})$ and Pyr were reported to induce cardiac malformations via the signaling pathways other than AhR (Huang et al., 2012; Incardona et al., 2011). Estrogen receptor (ER) pathway is also activated after exposure to $\mathrm{BaP}$ through the upregulation of cyp 19 aromatase, which might increase ER activity and ultimately induced the developmental toxicity in zebrafish (Hoffmann and Oris, 2006).

Exposure to the elevated levels of PPCPs may lead to the subtle effects (Fig. 6C). The continuous introduction of PPCPs to the environment and their accumulation in animals can induce irreversible toxic effect, e.g. DIC caused a substantial decline in the population of whitenecked vultures in Pakistan (Brausch and Rand, 2011; Oaks et al., 2004). Certain pharmaceuticals act as endocrine disruptors and cause reproductive and developmental toxicity through the induction of vitellogenesis in males (the generation of vitellogenin in plasma), intersex phenomenon, feminization of males and infertility (Lai et al., 2002). Among PCPs, UV filters and parabens also act as endocrine disrupting chemicals (Gomez et al., 2005). Further, the pharmaceuticals: TCS, TCC, GEM, CAF also exhibit potentials to disturb the endocrine system in different fish and other aquatic species (Foran et al., 2000; Kudrjashov et al., 2010; Rosal et al., 2010). In addition, the reduced hatching rates were observed in Japanese medaka after exposure to propranolol (Huggett et al., 2002). The exposure to synthetic musks and Carbamazepine (CBZ) induced oxidative stress in rainbow trout and goldfish (Fang et al., 2012; Li et al., 2010). Further, DIC induced gill disruptions and renal lesions in rainbow trout (Schwaiger et al., 2004). In addition, the mixture toxicity of CBZ, DIC and IBU on Daphnia magna revealed synergistic effects that were significantly higher than that of the individual pharmaceuticals (Cleuvers, 2003). Bioaccumulation of PPCPs is also responsible for their innate toxicity. Synthetic musks, disinfectants and UV filters are reported to accumulate in biological systems and caused adverse impacts via bio-magnification (Brausch and Rand, 2011).

\section{Concluding Remarks and Recommendations}

In summary, this review revealed the jolting environmental concentrations of DEHP and PAHs in the surface water resources of Asian counties, albeit the levels of emerging PPCPs were relatively low. The spatial distribution analysis of environmental levels and associated ecological risk of DEHP, PAHs and PPCPs further highlighted that the riverine systems of Asian countries especially that of China and India were expressed that alarming situation and need immediate rehabilitation measures. Comparatively, the riverine systems in Europe were relatively less contaminated and pose fewer risks to the ecological resources. Although considerable environmental regulations are existing to control legacy organic pollutants, the strict implementation of those regulations in Asian counties is specifically needed. In case of emerging environmental pollutants, such as PPCPs, the studies are still scarce and the environmental regulations are also not available. Therefore, more studies are recommended to unveil the current environmental occurrence, spatial distribution, sources and occurrence especially in South Asian countries. The petroleum products and incomplete combustion of fossil fuels were mentioned as the primary sources of PAHs in the environment, while DEHP is solely produced from plastic laden consumed products and medical appliances. Regarding the sources of PPCPs, the effluents from households, hospitals and PPCPs manufacturing units were listed as principal sources of PCPs and NSAIDs in the environment. PAHs were reported to cause the elicited toxicological concerns in terms of carcinogenicity, mutagenicity, developmental toxicity, and genotoxicity, while DEHP exhibited specific toxicity for reproductive, immune and nervous systems. PPCPs-appeared with least toxic concerns, such as developmental abnormalities, DNA damage, and genotoxicity. In a nutshell, this review unveiled the current alarming environmental levels of emerging and legacy organic pollutants and their toxicological impacts. On the basis of these findings, the strict implementation of environmental regulations is recommended to avoid future worst scenarios and ensure the ecological integrity and environmental safety.

\section{Acknowledgment}

The authors are grateful for the supports from the Three Hundred Leading Talents in Scientific and Technological Innovation Program of Chongqing (No. CSTCCXLJRC201714), the Key Application and Development Program of Chongqing Science and Technology Commission (No. cstc2014yykfC20004, cstc2014yykfC20002). 
Table S1: Comparative levels of DEHP reported in the surface waters worldwide

\begin{tabular}{|c|c|c|}
\hline Locations & DEHP levels $(\mu \mathrm{g} / \mathrm{L})$ & References \\
\hline Wuhan section, Yangtze River, China & 54.73 & (Wang et al., 2008) \\
\hline Hun River, China & 34.2 & (Li et al., 2015b) \\
\hline Yellow River, China & 24 & (Sha et al., 2006) \\
\hline Songhua River, China & 11.55 & (Gao et al., 2014) \\
\hline Pearl River Estuary, China & 12.1 & $(\mathrm{Li}, 2016)$ \\
\hline Jiulong River, China & 10.9 & (Li et al., 2016) \\
\hline Wujin River, China & 8.89 & (Zhang et al., 2011) \\
\hline Pearl River Delta, China & 8.84 & $(\mathrm{Li}, 2015)$ \\
\hline Jiangsu section, Yangtze River, China & 2.05 & (He et al., 2011b) \\
\hline Liao River, Anshan, China & 13050 & (Yu et al., 2011a) \\
\hline Kunming Lake, China & 1390 & (An and Jin, 2000) \\
\hline Xuanwu Lake, Yangtze River, China & 1299 & (Shen et al., 2010) \\
\hline Kuils River & 380 & (Olujimi et al., 2012) \\
\hline Velwatchers River & 280 & \\
\hline Mosselbank River & 139 & \\
\hline Vygekraal River & 62 & \\
\hline Diep River & 7 & \\
\hline Kuils River, South Africa & ND & \\
\hline Rivers of Eastern Cape, South Africa & 2306 & (Fatoki and Noma, 2002) \\
\hline Rivers and lakes, Germany & 98 & (Fromme et al., 2002) \\
\hline Seine River estuary,France & 6.44 & (Dargnat et al., 2009) \\
\hline River of France & 1.7 & (Tran et al., 2015) \\
\hline Bang Pa-kong River, Chao Phraya River, & $<1.10$ & (Sirivithayapakorn, 2010) \\
\hline \multicolumn{3}{|l|}{ Tha-chin River, Mae-klong River,Thailand } \\
\hline Kaveri River, India & 1.4 & (Selvaraj et al., 2015) \\
\hline Selangor River, Malaysia & 0.97 & (Veerasingam, 2013) \\
\hline Selangor River,Malaysia & 0.38 & (Santhi and Mustafa, 2013) \\
\hline Manzanares River and Jarama River,Spain & ND & (Dominguez et al., 2014) \\
\hline North-West River, Spain & $<0.44$ & (Regueiro et al., 2008) \\
\hline River, Spain & 0.17 & (Sanchez et al., 2011) \\
\hline
\end{tabular}

The values listed here are the high-end (max.) reported concentrations

Table S2: Comparative levels of $\Sigma$ PAHs reported in the surface waters of China and worldwide

\begin{tabular}{|c|c|c|}
\hline Locations & Concentration of $\Sigma \mathrm{PAHs}(\mathrm{ng} / \mathrm{L})$ & References \\
\hline Gao-ping River, Taiwan & 9400 & (Doong and Lin, 2004) \\
\hline Yellow River Delta, China & 334 & (Wang et al., 2009) \\
\hline Jiulong River Estuary, China & 26920 & (Maskaoui et al., 2002) \\
\hline Alexandria coast, Egypt & 523 & (El-Nemr and Abd-Allah, 2003) \\
\hline Tianjin, China & 1272 & (Shi et al., 2005) \\
\hline Kor River, Iran & 375 & (Kafilzadeh et al., 2011) \\
\hline Gomti River System, India & 75570 & (Malik et al., 2004) \\
\hline Daliao River watershed, China & 13448.5 & (Guo et al., 2007) \\
\hline Hangzhou City, China & 9663 & (Chen et al., 2004) \\
\hline Danube River, Hungarian & 357 & (Nagy et al., 2012) \\
\hline Bolgoda Lake, Sri Lanka & 127 & (Pathiratne et al., 2007) \\
\hline Tonghui River, China & 2651 & (Zhang et al., 2004) \\
\hline River Tiber, Italy & 72 & (Patrolecco et al., 2010) \\
\hline Chenab River, Pakistan & $436.66-1287.9$ & (Farooq et al., 2011) \\
\hline Odra river,Poland & $0.0-3349.9$ & (Wolska et al., 2003) \\
\hline Todos Os Santos Bay, Brazil & $0.0029-0.1079$ & (Jose Celino et al., 2012) \\
\hline Danube branch, Hungary & $6.7-3026$ & (Nagy et al., 2007) \\
\hline Danube River, Hungarian & $25-1208$ & (Nagy et al., 2013) \\
\hline Daya Bay, China & $4228-29325$ & (Zhoua and Maskaouib, 2003) \\
\hline Gomti River, India & $60-84210$ & (Farooq et al., 2011) \\
\hline Pearl River Delta, China & $944-6654$ & (Luo et al., 2004) \\
\hline Niteroi streams City, Brazil & $4-870$ & (Ribeiro et al., 2012) \\
\hline Hai River Basin estuary, China & $232.12-7596.56$ & (Yan et al., 2016) \\
\hline Soan River, Pakistan & $61-207$ & (Aziz et al., 2014) \\
\hline
\end{tabular}

The values listed here are the high-end (max.) reported concentrations 
Table S3: Comparative levels (ng/L) of PPCPs reported in the surface waters of China and worldwide

\begin{tabular}{|c|c|c|}
\hline River name and location & $\Sigma \mathrm{PCP}$ 's & Reference \\
\hline Kunyu, Tonghui, Liangshui Rivers, Beijing, China & 41.400 & (Li et al., 2016) \\
\hline Pearl River, Guangdong, China & 152.100 & (Yu et al., 2011b) \\
\hline Pearl River, Guangdong, China & 3204.000 & (Peng et al., 2008) \\
\hline \multirow[t]{2}{*}{ Yangtze River Zigui-Shanghai, China } & 26.000 & (Liu et al., 2015b) \\
\hline & 33.820 & (Zhang et al., 2015) \\
\hline \multirow[t]{2}{*}{ Sha River, Guangzhou, China } & 19.650 & \\
\hline & 65.700 & (Ramaswamy et al., 2011) \\
\hline Kaveri River, Tamilnadu, India & 79.800 & \\
\hline Reservoir, Guangdong, China & 178.000 & (Peng et al., 2014) \\
\hline \multirow[t]{2}{*}{ Geylang River, Singapore } & 0.370 & (Xu et al., 2011; Wang and Kelly, 2016) \\
\hline & 1.580 & (Yamagishi et al., 1983) \\
\hline Kallang River, Singapore & 0.300 & \\
\hline Tama River, Japan & 0.023 & \\
\hline Elbe River, Germany & 9.000 & (Gatermann et al., 1998) \\
\hline
\end{tabular}

The values listed here are the high-end (max.) reported concentrations. $\square$ PCPs included methylparaben (MP), propylparaben (PP) and musk xylene (MX)

Table S4: Comparative levels (ng/L) of $\Sigma$ NSAIDs reported in the surface waters of China and worldwide.

\begin{tabular}{|c|c|c|}
\hline Location & $\Sigma$ NSAIDs & Reference \\
\hline Pearl River, Guangdong, China & 1745.00 & (Peng et al., 2008) \\
\hline Kaveri River, Tamilnadu, India & 0.00 & (Ramaswamy et al., 2011) \\
\hline Reservoir, Guangdong & 40.50 & (Peng et al., 2014) \\
\hline Geylang River, Singapore & 91.00 & (Xu et al., 2011; Wang and Kelly, 2016) \\
\hline Kallang River, Singapore & 56.00 & (Xu et al., 2011; Wang and Kelly, 2016) \\
\hline Beiyun River basin Beijing, China & 121.60 & (Ma et al., 2017) \\
\hline Danube River, Romania & 188.00 & (Chitescu et al., 2015) \\
\hline Mino River, Spain & 46.00 & (Iglesias et al., 2014) \\
\hline Dongting Lake, Hunan, China & 249.80 & (Barbosa et al., 2016b) \\
\hline Haihe River System, Beijing and Tianjin & 190.00 & (Heeb et al., 2012) \\
\hline Centeral and lower Yangtze River, China & 99.30 & (Wu et al., 2014) \\
\hline Mississippi River, Louisiana, USA & 169.00 & (Zhang et al., 2007) \\
\hline Huangpu River, Shanghai, China & 142.60 & (Gao et al., 2014) \\
\hline Yangtze River, Nanjing, China & 442.00 & (Liu et al., 2015a) \\
\hline Llobregat River, Castellgali, Spain & 226.00 & (Farre et al., 2012) \\
\hline Cardener River, Castellgali, Spain & 484.00 & (Farre et al., 2012) \\
\hline Singapore River, Singapore & 110.00 & (Xu et al., 2011) \\
\hline Ananymous Resvoir, Singapore & 10.85 & (You et al., 2015) \\
\hline Tributaries & 22.05 & (You et al., 2015) \\
\hline Pearl River, Guangdong & 755.00 & (Zhao et al., 2009) \\
\hline Pearl River, Guangdong & 960.00 & (Zhao et al., 2011) \\
\hline Pearl River Delta, Guangzhou, China & 442.00 & (Huang et al., 2011) \\
\hline Yangtze River Shanghai, China & 843.00 & (Yang et al., 2011) \\
\hline \multirow[t]{2}{*}{ Haihe River, Tianjin, China } & 152.20 & (Li et al., 2010) \\
\hline & 46.40 & (Li et al., 2010) \\
\hline \multirow[t]{2}{*}{ Liaohe River, Liaoning } & 155.00 & (Li et al., 2010) \\
\hline & 963.00 & (Li et al., 2010) \\
\hline \multirow[t]{2}{*}{ Yellow River, China } & 74.20 & (Li et al., 2010) \\
\hline & 552.00 & (Li et al., 2010) \\
\hline Zhangweinanyunhe River, Northern China & 29.40 & (Cao et al., 2010) \\
\hline Llobregat River, Spain & 280.00 & (Aldekoa et al., 2013) \\
\hline
\end{tabular}

The values listed here are the high-end (max.) reported concentrations. $\Sigma$ NSAIDs included naproxen (NAP), ibuprofen (IBU) and diclofenac (DIC)

\section{Author's Contributions}

Yi Liu and Muhammad Junaid: Contributed equally to the manuscript. Extracted and analyzed the data and wrote the first draft.
Chun-Di Chen Naima Hamid: Develop illustration, analyze and revise the paper.

De-Sheng Pei: Conceived and designed this review, wrote the paper and revised the paper. 


\section{Conflict of Interest}

The authors declare no conflict of interest.

\section{References}

Akingbemi, B.T., R. Ge, G.R. Klinefelter, B.R. Zirkin and M.P. Hardy, 2004. Phthalate-induced Leydig cell hyperplasia is associated with multiple endocrine disturbances. Proc. Nat. Acad. Sci. USA, 101: 775-80. DOI: 10.1073/pnas.0305977101

Aldekoa, J., C. Medici, V. Osorio, S. Pérez and R. Marcé et al., 2013. Modelling the emerging pollutant diclofenac with the GREAT-ER model: Application to the Llobregat River Basin. J. Hazardous Mater., 263: 207-213. DOI: 10.1016/j.jhazmat.2013.08.057

An, S. and Z. Jin, 2000. Detection and removal of organic pollutants in Kunming Lake's water in Beijing. Environ. Chem., 12: 284-288.

ATDSR, 1995. Toxicological profile for Polycyclic Aromatic Hydrocarbons (PAHs) by Agency for Toxic Substances and Disease Registry (ATSDR). Department of Health and Human Services.

ATSDR, 2002. Toxicological profile for di(2-ethylhexyl) phthalate by Agency for Toxic Substances and Disease Registry (ATSDR).

Aydin, E. and I. Talinli, 2013. Analysis, occurrence and fate of commonly used pharmaceuticals and hormones in the Buyukcekmece Watershed, Turkey. Chemosphere, 90: 2004-2012. DOI: $10.1016 /$ j.chemosphere.2012.10.074

Aziz, F., J.H. Syed, R.N. Malik, A. Katsoyiannis and A. Mahmood et al., 2014. Occurrence of polycyclic aromatic hydrocarbons in the Soan River, Pakistan: Insights into distribution, composition, sources and ecological risk assessment. Ecotoxicol. Environ. Safety, 109: 77-84.

DOI: $10.1016 /$ j.ecoenv.2014.07.022

Barbosa, M.O., A.R. Ribeiro, M.F.R. Pereira and A.M.T. Silva, 2016b. Eco-friendly LC-MS/MS method for analysis of multi-class micropollutants in tap, fountain and well water from northern Portugal. Anal. Bioanalytical Chem., 408: 8355-8367. DOI: $10.1007 / \mathrm{s} 00216-016-9952-7$

Barbosa, M.O., N.F. Moreira, A.R. Ribeiro, M.F. Pereira and A.M. Silva, 2016a. Occurrence and removal of organic micropollutants: An overview of the watch list of EU Decision 2015/495. Water Res., 94: 257-257. DOI: 10.1016/j.watres.2016.02.047

Benotti, M.J. and B.J. Brownawell, 2009. Microbial degradation of pharmaceuticals in estuarine and coastal seawater. Environ. Poll., 157: 994-1002. DOI: 10.1016/j.envpol.2008.10.009

Besse, J.P. and J. Garric, 2008. Human pharmaceuticals in surface waters. Toxicol. Lett., 176: 104-123. DOI: $10.1016 /$ j.toxlet.2007.10.012
Botelho, G.G., M. Golin, A.C. Bufalo, R.N. Morais and P.R. Dalsenter et al., 2009. Reproductive effects of di(2-ethylhexyl)phthalate in immature male rats and its relation to cholesterol, testosterone and thyroxin levels. Arch. Environ. Contamin. Toxicol., 57: 777-784. DOI: 10.1007/s00244-009-9317-8

Brausch, J.M. and G.M. Rand, 2011. A review of personal care products in the aquatic environment: Environmental concentrations and toxicity. Chemosphere, 82: 1518-1532.

DOI: 10.1016/j.chemosphere.2010.11.018

Buxton, H.T. and D.W. Kolpin, 2005. Pharmaceuticals, hormones and other organic wastewater contaminants in U.S. Streams. Fact Sheet. vol 36. U.S. Geological Survey, Reston, VA, United States.

Caldwell, J.C., 2012. DEHP: Genotoxicity and potential carcinogenic mechanisms-a review. Mutat. Res., 751: 82-157. DOI: 10.1016/j.mrrev.2012.03.001

Caliman, F.A. and M. Gavrilescu, 2009. Pharmaceuticals, personal care products and endocrine disrupting agents in the environment - a review. CLEAN - Soil Air Water, 37: 277-303. DOI: $10.1002 /$ clen.200900038

Cao, J.L., J.H. Shi, R. Han, Y.X. Li and Z.F. Yang, 2010. Seasonal variations in the occurrence and distribution of estrogens and pharmaceuticals in the Zhangweinanyun River System. Chinese Sci. Bull., 55: 3138-3144. DOI: 10.1007/s11434-010-3158-8

Cao, Z., Y. Wang, Y. Ma, Z. Xu and G. Shi et al., 2005. Occurrence and distribution of polycyclic aromatic hydrocarbons in reclaimed water and surface water of Tianjin, China. J. Hazardous Mater., 122: 51-59. DOI: $10.1016 /$ j.jhazmat.2005.04.003

CDC, 2010. Prescription drug use continues to increase: U.S. prescription drug data for 2007-2008.

CDER, 1998. Guidance for industry-environmental assessment of human drug and biologics applications. Center for Drug Evaluation and Research (CDER), United States (US).

Chan, C.M., K.H. Wong, W.K. Chung, T.S. Chow and P.K. Wong, 2007. Photocatalytic degradation of di(2-ethylhexyl)phthalate adsorbed by chitin A. Water Sci. Technol., 56: 125-34. DOI: $10.2166 /$ wst.2007.685

Chen, B., X. Xuan, L. Zhu, J. Wang and Y. Gao et al., 2004. Distributions of polycyclic aromatic hydrocarbons in surface waters, sediments and soils of Hangzhou City, China. Water Res., 38: 3558-3568. DOI: 10.1016/j.watres.2004.05.013

Chen, L., Y. Zhao, L. Li, B. Chen and Y. Zhang, 2012. Exposure assessment of phthalates in nonoccupational populations in China. Sci. Total Environ., 427-428: 60-69. DOI: $10.1016 /$ j.scitotenv.2012.03.090 
Chen, M.L., J.S. Chen, C.L. Tang and I.F. Mao, 2008. The internal exposure of Taiwanese to phthalate--an evidence of intensive use of plastic materials. Environ. Int., 34: 79-85.

DOI: 10.1016/j.envint.2007.07.004

Chen, Y., X. Xi, G. Yu, Q. Cao and B. Wang et al., 2015. Pharmaceutical compounds in aquatic environment in China: Locally screening and environmental risk assessment. Frontiers Environ. Sci. Eng., 9: 394-401. DOI: $10.1007 / \mathrm{s} 11783-014-0653-1$

Chitescu, C.L., G. Kaklamanos, A.I. Nicolau and A.A.M. Stolker, 2015. High sensitive multiresidue analysis of pharmaceuticals and antifungals in surface water using U-HPLC-Q-Exactive Orbitrap HRMS. Application to the Danube river basin on the Romanian territory. Sci. Total Environ., 532: 501-511. DOI: 10.1016/j.scitotenv.2015.06.010

Cleuvers, M., 2003. Aquatic ecotoxicity of pharmaceuticals including the assessment of combination effects. Toxicol. Lett., 142: 185-194. DOI: $10.1016 / \mathrm{S} 0378-4274(03) 00068-7$

Dai, G., B. Wang, J. Huang, R. Dong and S. Deng et al., 2015. Occurrence and source apportionment of pharmaceuticals and personal care products in the Beiyun River of Beijing, China. Chemosphere, 119: 1033-1039.

DOI: 10.1016/j.chemosphere.2014.08.056

Dargnat, C., M. Blanchard, M. Chevreuil and M.J. Teil, 2009. Occurrence of phthalate esters in the Seine River estuary (France). Hydrol. Processes, 23: 1192-1201. DOI: 10.1002/hyp.7245

Deblonde, T., C. Cossuleguille and P. Hartemann, 2011. Emerging pollutants in wastewater: A review of the literature. Int. J. Hygiene Environ. Health, 214: 442-448. DOI: 10.1016/j.ijheh.2011.08.002

Desvergne, B., J.N. Feige, C. Casalscasas, M.L. Aubert and S. Nef et al., 2009. PPAR-mediated activity of phthalates: A link to the obesity epidemic? Molecular Cellular Endocrinol., 304: 43-48. DOI: $10.1016 /$ j.mce.2009.02.017

Dominguez, M.N., A.S. Gonzalez and Y. Valcarcel, 2014. Phthalate occurrence in rivers and tap water from central Spain. Sci. Total Environ., 500: 139-146. DOI: 10.1016/j.scitotenv.2014.08.098

Dong, Z., D.B. Senn, R.E. Moran and J.P. Shine, 2013. Prioritizing environmental risk of prescription pharmaceuticals. Regulatory Toxicol. Pharmacol., 65: 60-67. DOI: 10.1016/j.yrtph.2012.07.003

Doong, R.A. and Y.T. Lin, 2004. Characterization and distribution of polycyclic aromatic hydrocarbon contaminations in surface sediment and water from Gao-ping River, Taiwan. Water Res., 38: 1733-44. DOI: $10.1016 /$ j.watres.2003.12.042
El-Nemr, A. and M.A. Abd-Allah, 2003. Contamination of Polycyclic Aromatic Hydrocarbons (PAHs) in microlayer and subsurface waters along Alexandria coast, Egypt. Chemosphere, 52: 1711-1716. DOI: $10.1016 / \mathrm{s} 0045-6535(03) 00300-\mathrm{x}$

EMA, 2006. Note for guidance on environmental risk assessment of medicinal products for human use. CPMP/SWP $/ 4447 / 00$. European Medicines Agency, London.

EU, 2008. Bis(2-ethylhexyl) Phthalate (DEHP). Summary Risk Assessment Report. EUR 23384 EN/2.

Fang, C., G. Jie and Q. Zhou, 2012. Toxicity assessment of simulated urban runoff containing polycyclic musks and cadmium in Carassius auratus using oxidative stress biomarkers. Environ. Poll., 162: 91-97.

Farooq, S., S.A.M.A.S. Eqani, R.N. Malik, A. Katsoyiannis and G. Zhang et al., 2011. Occurrence, finger printing and ecological risk assessment of Polycyclic Aromatic Hydrocarbons (PAHs) in the Chenab River, Pakistan. J. Environ. Monit., 13: 3207-3215. DOI: 10.1039/c1 em10421g

Farre, M., L. Kantiani, M. Petrovic, S. Pérez and D. Barceló, 2012. Achievements and future trends in the analysis of emerging organic contaminants in environmental samples by mass spectrometry and bioanalytical techniques. J. Chromatography A, 1259: 86-99. DOI: 10.1016/j.chroma.2012.07.024

Fatoki, O.S. and A. Noma, 2002. Solid phase extraction method for selective determination of phthalate esters in the aquatic environment. Water Air Soil Pollut., 140: 85-98. DOI: 10.1023/A: 1020134707450

Fattakassinos, D., C. Manaia, T.U. Berendonk, E. Cytryn and J. Bayona et al., 2015. COST Action ES1403: New and Emerging challenges and opportunities in wastewater reuse (NEREUS). Environ. Sci. Pollut. Res. Int., 22: 7183-7186. DOI: $10.1007 / \mathrm{s} 11356-015-4278-0$

FDA, 1969. Code of federal regulations title 21, PART 25 environmental impact considerations. U.S. Food and Drug Administration.

Feige, J.N., A. Gerber, C. Casals-Casas, Q. Yang and C. Winkler et al., 2010. The pollutant diethylhexyl phthalate regulates hepatic energy metabolism via species-specific ppar $\alpha$-dependent mechanisms. Environ. Health Perspectives, 118: 234-241. DOI: $10.1289 /$ ehp.0901217

Fernandes, M.B., M.A. Sicre, A. Boireau and J. Tronczynski, 1997. Polyaromatic Hydrocarbon (PAH) distributions in the Seine River and its estuary. Marine Pollut. Bull., 34: 857-867. DOI: $10.1016 / \mathrm{S} 0025-326 \mathrm{X}(97) 00063-5$

Foran, C.M., E.R. Bennett and W.H. Benson, 2000. Developmental evaluation of a potential nonsteroidal estrogen: Triclosan. Marine Environ. Res., 50: 153-156. DOI: 10.1016/S0141-1136(00)00080-5 
Franco, M.R., R.U.H. Ramírez, A.M. Calafat, M.E. Cebrián and L.L. Needham et al., 2011. Personal care product use and urinary levels of phthalate metabolites in Mexican women. Environ. Int., 37: 867-871. DOI: 10.1016/j.envint.2011.02.014

Fromme, H., T. Küchler, T. Otto, K. Pilz and J. Müller et al., 2002. Occurrence of phthalates and bisphenol $\mathrm{A}$ and $\mathrm{F}$ in the environment. Water Res., 36: 1429-1438. DOI: $10.1016 / \mathrm{S} 0043-1354(01) 00367-0$

Gao, D., Z. Li, Z. Wen and N. Ren, 2014. Occurrence and fate of phthalate esters in full-scale domestic wastewater treatment plants and their impact on receiving waters along the Songhua River in China. Chemosphere, 95: 24-32.

DOI: 10.1016/j.chemosphere.2013.08.009

Gao, Q., Y. Li, Q. Cheng, M. Yu and B. Hu et al., 2016. Analysis and assessment of the nutrients, biochemical indexes and heavy metals in the Three Gorges Reservoir, China, from 2008 to 2013. Water Res., 92: 262-274.

DOI: $10.1016 /$ j.watres.2015.12.055

Gatermann, R., H. Huhnerfuss, G. Rimkus, A. Attar and A. Kettrup, 1998. Occurrence of musk xylene and musk ketone metabolites in the aquatic environment. Chemosphere, 36: 2535-2547.

DOI: $10.1016 / \mathrm{S} 0045-6535(97) 10208-9$

Gavrilescu, M., K. Demnerová, J. Aamand, S. Agathos and F. Fava, 2015. Emerging pollutants in the environment: Present and future challenges in biomonitoring, ecological risks and bioremediation. New Biotechnol., 32: 147-156.

DOI: $10.1016 /$ j.nbt.2014.01.001

Gleick, P., 2009. The world's water 2008-2009 data, three gorges dam project, Yangtze River China. Water Brief.

Gomez, E., A. Pillon, H. Fenet, D. Rosain and M.J. Duchesne et al., 2005. Estrogenic activity of cosmetic components in reporter cell lines: Parabens, UV screens and musks. J. Toxicol. Environ. Health, 68: 239-251. DOI: $10.1080 / 15287390590895054$

Goodale, B.C., S.C. Tilton, M.M. Corvi, G.R. Wilson and D.B. Janszen et al., 2013. Structurally distinct polycyclic aromatic hydrocarbons induce differential transcriptional responses in developing zebrafish. Toxicol. Applied Pharmacol., 272: 656-670. DOI: 10.1016/j.taap.2013.04.024

Gorito, A.M., A.R. Ribeiro, C.M.R. Almeida and A.M.T. Silva, 2017. A review on the application of constructed wetlands for the removal of priority substances and contaminants of emerging concern listed in recently launched EU legislation. Environ. Pollut., 227: 428-443.

DOI: $10.1016 /$ j.envpol.2017.04.060
Guo, J.X. and J. Fang, 2012. The Distribution of nalkanes and polycyclic aromatic hydrocarbons in Water of Taihu Lake. Proc. Environ. Sci., 12: 258-264. DOI: 10.1016/j.proenv.2012.01.275

Guo, W., M. He, Z. Yang, C. Lin and X. Quan et al., 2007. Distribution of polycyclic aromatic hydrocarbons in water, suspended particulate matter and sediment from Daliao River watershed, China. Chemosphere, 68: 93-104 DOI: 10.1016/j.chemosphere.2006.12.072

Hamid, N., J.H. Syed, A. Kamal, F. Aziz and S. Tanveer et al., 2016. A review on the abundance, distribution and eco-biological risks of PAHs in the key environmental matrices of South Asia. Rev. Environ. Contam. Toxicol., 240: 1-30.

DOI: $10.1007 / 39820155007$

Han, D. and M.J. Currell, 2016. Persistent organic pollutants in China's surface water systems. Sci. Total Environ., 580: 602-625.

DOI: $10.1016 /$ j.scitotenv.2016.12.007

Han, D., M.J. Currell and G. Cao, 2016. Deep challenges for China's war on water pollution. Environ. Poll., 218: 1222-1233. DOI: 10.1016/j.envpol.2016.08.078

Hawliczek, A., B. Nota, P. Cenijn, J. Kamstra and B. Pieterse et al., 2012. Developmental toxicity and endocrine disrupting potency of 4-azapyrene, benzo[b]fluorene and retene in the zebrafish Danio rerio. Reproductive Toxicol., 33: 213-223.

DOI: 10.1016/j.reprotox.2011.11.001

He, C., Z. Zuo, X. Shi, R. Li and D. Chen et al., $2011 \mathrm{a}$. Effects of benzo(a)pyrene on the skeletal development of Sebastiscus marmoratus embryos and the molecular mechanism involved. Aquatic Toxicol., 101: 335-341. DOI: 10.1016/j.aquatox.2010.11.008

He, H., G.J. Hu, C. Sun, S.L. Chen and M.N. Yang et al., $2011 \mathrm{~b}$. Trace analysis of persistent toxic substances in the main stream of Jiangsu section of the Yangtze River, China. Environ. Sci. Poll. Res., 18: 638-648 DOI: $10.1007 / \mathrm{s} 11356-010-0414-\mathrm{z}$

Heberer, T., 2002. Occurrence, fate and removal of pharmaceutical residues in the aquatic environment: A review of recent research data. Toxicol. Lett., 131: 5-17. DOI: 10.1016/S0378-4274(02)00041-3

Heeb, F., H. Singer, B Pernetcoudrier, W. Qi and H. Liu et al., 2012. Organic micropollutants in rivers downstream of the megacity Beijing: Sources and mass fluxes in a large-scale wastewater irrigation system. Environ. Sci. Technol., 46: 8680-8688. DOI: $10.1021 / \mathrm{es} 301912 \mathrm{q}$

Hernando, M.D., M. Mezcua, A.R. Fernández-Alba and D. Barceló, 2006. Environmental risk assessment of pharmaceutical residues in wastewater effluents, surface waters and sediments. Talanta, 69: 334-342. DOI: $10.1016 /$ j.talanta.2005.09.037 
Hoffmann, J.L. and J.T. Oris, 2006. Altered gene expression: A mechanism for reproductive toxicity in zebrafish exposed to benzo[a]pyrene. Aquatic Toxicol., 78: 332-340.

DOI: 10.1016/j.aquatox.2006.04.007

Hook, S.E., M.A. Lampi, E.J. Febbo, J.A. Ward and T.F. Parkerton, 2010. Hepatic gene expression in rainbow trout (Oncorhynchus mykiss) exposed to different hydrocarbon mixtures. Environ. Toxicol. Chem., 29: 2034-2043. DOI: 10.1002/etc.245

Huang, L., C. Wang, Y. Zhang, J. Li and Y. Zhong et al., 2012. Benzo[a]pyrene exposure influences the cardiac development and the expression of cardiovascular relative genes in zebrafish (Danio rerio) embryos. Chemosphere, 87: 369-375.

DOI: $10.1016 / \mathrm{j}$.chemosphere.2011.12.026

Huang, L., C. Wang, Y. Zhang, M. Wu and Z. Zuo, 2013. Phenanthrene causes ocular developmental toxicity in zebrafish embryos and the possible mechanisms involved. J. Hazardous Mater., 261: 172-180. DOI: 10.1016/j.jhazmat.2013.07.030

Huang, Q., Y. Yu, C. Tang, K. Zhang and J. Cui et al., 2011. Occurrence and behavior of non-steroidal antiinflammatory drugs and lipid regulators in wastewater and urban river water of the Pearl River Delta, South China. J. Environ. Monitor., 13: 855-863.

DOI: $10.1039 / \mathrm{C} 1 \mathrm{EM} 10015 \mathrm{G}$

Huggett, D.B., B.W. Brooks, B. Peterson, C.M. Foran and D. Schlenk, 2002. Toxicity of select beta adrenergic receptor-blocking pharmaceuticals (Bblockers) on aquatic organisms. Arch. Environ. Contamin. Toxicol., 43: 229-235.

DOI: $10.1007 / \mathrm{s} 00244-002-1182-7$

Hurst, C.H. and D.J. Waxman, 2004. Environmental phthalate monoesters activate pregnane $\mathrm{X}$ receptormediated transcription. Toxicol. Applied Pharmacol., 199: 266-274. DOI: 10.1016/j.taap.2003.11.028

Iglesias, A., C. Nebot, B.I. Vázquez, C. Coronel-Olivares and C.M.F. Abuín et al., 2014. Monitoring the presence of 13 active compounds in surface water collected from rural areas in Northwestern Spain. Int. J. Environ. Res. Public Health, 11: 5251-5272. DOI: 10.3390/ijerph110505251

Incardona, J.P., T.K. Collier and N.L. Scholz, 2004. Defects in cardiac function precede morphological abnormalities in fish embryos exposed to polycyclic aromatic hydrocarbons. Toxicol. Applied Pharmacol., 196: 191-205.

DOI: $10.1016 /$ j.taap.2003.11.026

Incardona, J.P., T.L. Linbo and N.L. Scholz, 2011. Cardiac toxicity of 5-ring polycyclic aromatic hydrocarbons is differentially dependent on the aryl hydrocarbon receptor 2 isoform during zebrafish development. Toxicol. Applied Pharmacol., 257: 242-249. DOI: 10.1016/j.taap.2011.09.010
Jelic, A., M. Gros, A. Ginebreda, R. Cespedes-Sánchez and F. Ventura et al., 2011. Occurrence, partition and removal of pharmaceuticals in sewage water and sludge during wastewater treatment. Water Res., 45: 1165-1176. DOI: 10.1016/j.watres.2010.11.010

Jia, P.P., Y.B. Ma, C.J. Lu, Z. Mirza and W. Zhang et al., 2016. The effects of disturbance on Hypothalamus-Pituitary-Thyroid (HPT) axis in zebrafish larvae after exposure to DEHP. Plos One, 11: e0155762-e0155762.

DOI: $10.1371 /$ journal.pone.0155762

Jjemba, P.K., 2006. Excretion and ecotoxicity of pharmaceutical and personal care products in the environment. Ecotoxicol. Environ. Safety, 63: 113-130. DOI: 10.1016/j.ecoenv.2004.11.011

Jones, O.A.H., N. Voulvoulis and J.N. Lester, 2002. Aquatic environmental assessment of the top 25 English prescription pharmaceuticals. Water Res., 36: 5013-5022. DOI: 10.1016/S0043-1354(02)00227-0

Jose Celino, J., H. Xavier Corseuil, M. Fernandes and G. Mara Hadlich, 2012. Persistent toxic substances in surface water of Todos Os Santos Bay, Brazil. Resources Environ., 2: 141-149 DOI: $10.5923 /$ j.re.20120204.03

Jung, K.H., J.H. Noh, J.W. Eun, J.K. Kim and H.J. Bae et al., 2011. Molecular signature for early detection and prediction of polycyclic aromatic hydrocarbons in peripheral blood. Environ. Sci. Technol., 45: 300-306. DOI: 10.1021/es101840s

Jung, K.H., J.K. Kim, J.H. Noh, J.W. Eun and H.J. Bae et al., 2013. Characteristic molecular signature for the early detection and prediction of polycyclic aromatic hydrocarbons in rat liver. Toxicol. Lett., 216: 1-8. DOI: 10.1016/j.toxlet.2012.11.001

Kafilzadeh, F., 2015. Distribution and sources of polycyclic aromatic hydrocarbons in water and sediments of the Soltan Abad River, Iran. Egypt. J. Aquatic Res., 41: 227-231.

DOI: 10.1016/j.ejar.2015.06.004

Kafilzadeh, F., A.H Shiva and R. Malekpour, 2011. Determination of Polycyclic Aromatic Hydrocarbons (PAHs) in water and sediments of the Kor River, Iran. Scientific Res., 10: 01-07.

Ke, H., A.D. Soares, H. Adejumo, M. Mcdiarmid and K. Squibb et al., 2015. Detection of a wide variety of human and veterinary fluoroquinolone antibiotics in municipal wastewater and wastewater-impacted surface water. J. Pharmaceutical Biomed. Anal., 106: 136-143. DOI: 10.1016/j.jpba.2014.11.020

Kim, K.H., S.A. Jahan, E. Kabir and R.J. Brown, 2013. A review of airborne Polycyclic Aromatic hydrocarbons (PAHs) and their human health effects. Environ. Int., 60: 71-80. DOI: $10.1016 /$ j.envint.2013.07.019 
Kim, S.D., J. Cho, I.S. Kim, B.J. Vanderford and S.A. Snyder, 2007. Occurrence and removal of pharmaceuticals and endocrine disruptors in South Korean surface, drinking and waste waters. Water Res., 41: 1013-1021.

DOI: $10.1016 /$ j.watres.2006.06.034

Koch, H.M., B. Rossbach, H. Drexler and J. Angerer, $2003 \mathrm{~b}$. Internal exposure of the general population to DEHP and other phthalates--determination of secondary and primary phthalate monoester metabolites in urine. Environ. Res., 93: 177-185. DOI: 10.1016/S0013-9351(03)00083-5

Koch, H.M., L.M. Gonzalezreche and J. Angerer, 2003a. On-line clean-up by multidimensional liquid chromatography-electrospray ionization tandem mass spectrometry for high throughput quantification of primary and secondary phthalate metabolites in human urine. J. Chromatography B, 784: 169-182. DOI: $10.1016 / \mathrm{S} 1570-0232(02) 00785-7$

Kolpin, D.W., E.T. Furlong, M.T. Meyer, E.M. Thurman and S.D. Zaugg et al., 2002. Pharmaceuticals, hormones and other organic wastewater contaminants in U.S. streams, 1999-2000: A national reconnaissance. Environ. Sci. Technol., 36: 1202-1211. DOI: 10.1021/es011055j

Kolpin, D.W., M. Skopec, M.T. Meyer, E.T. Furlong and S.D. Zaugg, 2004. Urban contribution of pharmaceuticals and other organic wastewater contaminants to streams during differing flow conditions. Sci. Total Environ., 328: 119-130.

DOI: 10.1016/j.scitotenv.2004.01.015

Koniecki, D., R. Wang, R.P. Moody and J. Zhu, 2011. Phthalates in cosmetic and personal care products: Concentrations and possible dermal exposure. Environ. Res., 111: 329-336.

DOI: $10.1016 /$ j.envres.2011.01.013

Kudrjashov, B.A., S.M. Strukova, N.M. Solodenko and L.A. Lyapina, 2010. Growth inhibiting effects of twelve antibacterial agents and their mixtures on the freshwater microalga Pseudokirchneriella subcapitata. Environ. Toxicol. Chem., 27: 1201-1208.

Lai, K.M., M.D. Scrimshaw and J.N. Lester, 2002. The effects of natural and synthetic steroid estrogens in relation to their environmental occurrence [Review]. Critical Rev. Toxicol., 32: 113-132. DOI: 10.1080/20024091064192

Lee, I.S., S.H. Lee and J.E. Oh, 2010. Occurrence and fate of synthetic musk compounds in water environment. Water Res., 44: 214-222.

DOI: 10.1016/j.watres.2009.08.049

Lee, M.L., M.V. Novotny and K.D. Bartle, 1981. Analytical Chemistry of Polycyclic Aromatic Compounds. Academic Press, New York.
Li, B., X. Hu, R. Liu, P. Zeng and Y. Song, 2015a. Occurrence and distribution of phthalic acid esters and phenols in Hun River Watersheds. Environ. Earth Sci., 73: 5095-5106. DOI: $10.1007 / \mathrm{s} 12665-015-4299-5$

Li, Q., Y. Zeng, Y.Q. Fan and X.Y. Liu, 2006. Distribution of Polycyclic Aromatic Hydrocarbons (PAHs) in Lanzhou reach of the Yellow River. Chin J. Health Lab. Technol., 16: 1108-1109.

Li, R., J. Liang, Z. Gong, N. Zhang and H. Duan, 2016. Occurrence, spatial distribution, historical trend and ecological risk of phthalate esters in the Jiulong River, Southeast China. Sci. Total Environ., 580: 10-20. DOI: 10.1016/j.scitotenv.2016.11.190

Li, T., P. Yin, L. Zhao, G. Wang and Q.J. Yu et al., 2015b. Spatial-temporal distribution of phthalate esters from riverine outlets of Pearl River Delta in China. Water Sci. Technol., 71: 183-90.

DOI: $10.2166 /$ wst.2014.485

Li, W.C., 2014. Occurrence, sources and fate of pharmaceuticals in aquatic environment and soil. Environ. Poll., 187: 193-201. DOI: 10.1016/j.envpol.2014.01.015

Li, X.Y.P. and L. Zhao, 2016. Phthalate esters in water and surface sediments of the Pearl River Estuary: distribution, ecological and human health risks. Environ. Sci. Poll. Res., 23: 1-9. DOI: $10.1007 / \mathrm{s} 11356-016-7143-\mathrm{x}$

Li, Z.H., J. Velisek, V. Zlabek, R. Grabic and J. Machova et al., 2010. Hepatic antioxidant status and hematological parameters in rainbow trout, Oncorhynchus mykiss, after chronic exposure to carbamazepine. Chemico-Biol. Int., 183: 98-104. DOI: 10.1016/j.cbi.2009.09.009

Lin, C., C.J. Lee, W.M. Mao and F. Nadim, 2009. Identifying the potential sources of di-(2-ethylhexyl) phthalate contamination in the sediment of the Houjing River in southern Taiwan. J. Hazardous Mater., 161: 270-275. DOI: $10.1016 /$ j.jhazmat.2008.03.082

Liu, C., L. Zhao, L. Wei and L. Li, 2015a. DEHP reduces thyroid hormones via interacting with hormone synthesis-related proteins, deiodinases, transthyretin, receptors, and hepatic enzymes in rats. Environ. Sci. Poll. Res., 22: 12711-12719. DOI: $10.1007 / \mathrm{s} 11356-015-4567-7$

Liu, J., G. Lu, Z. Xie, Z. Zhang and S. Li et al., 2015 b. Occurrence, bioaccumulation and risk assessment of lipophilic pharmaceutically active compounds in the downstream rivers of sewage treatment plants. Sci. Total Environ., 511: 54-62.

DOI: $10.1016 /$ j.scitotenv.2014.12.033

Liu, J.L. and M.H. Wong, 2013. Pharmaceuticals and Personal Care Products (PPCPs): A review on environmental contamination in China. Environ. Int., 59: 208-224. DOI: 10.1016/j.envint.2013.06.012 
Liu, N., Y. Wang, Q. Yang, Y. Lv and X. Jin et al., 2016. Probabilistic assessment of risks of Diethylhexyl Phthalate (DEHP) in surface waters of China on reproduction of fish. Environ. Poll., 213: 482-488. DOI: 10.1016/j.envpol.2016.03.005

Liu, X., J. Shi, T. Bo, H. Zhang and W. Wu et al., 2014. Occurrence of phthalic acid esters in source waters: a nationwide survey in China during the period of 2009-2012. Environ. Poll., 184: 262-270.

DOI: 10.1016/j.envpol.2013.08.035

Loganathan, B.G. and P.K.S. Lam, 2012. Global Contamination Trends of Persistent Organic Chemicals. 1st Edn., CRC Press, Taylor and Francis Inc, Bosa Roca, USA.

Luo, X., B. Mai, Q. Yang, J. Fu and G. Sheng et al., 2004. Polycyclic Aromatic Hydrocarbons (PAHs) and organochlorine pesticides in water columns from the Pearl River and the Macao harbor in the Pearl River Delta in South China. Mar. Poll. Bull., 48: 1102-1115.

DOI: 10.1016/j.marpolbul.2003.12.018

Luo, Y., W. Guo, H.H. Ngo, L.D. Nghiem and F.I. Hai et al., 2014. A review on the occurrence of micropollutants in the aquatic environment and their fate and removal during wastewater treatment. Sci. Total Environ., 474: 619-41.

DOI: 10.1016/j.scitotenv.2013.12.065

Ma, Y.B., P.P. Jia, M. Junaid, L. Yang and C.J. Lu et al., 2017. Reproductive effects linked to DNA methylation in male zebrafish chronically exposed to environmentally relevant concentrations of di-(2-ethylhexyl) phthalate. Environ. Poll., 237: 1050-1061. DOI: $10.1016 /$ j.envpol.2017.11.025

Mackerer, C.R., 1996. Developmental toxicity of clarified slurry oil, syntower bottoms and distillate aromatic extract administered as a single oral dose to pregnant rats. J. Toxicol. Environ. Health, 49: 45-66.

DOI: $10.1080 / 009841096160989$

Magdouli, S., R. Daghrir, S.K. Brar, P. Drogui and R.D. Tyagi, 2013. Di 2-ethylhexylphtalate in the aquatic and terrestrial environment: A critical review. J. Environ. Manage., 127: 36-49. DOI: 10.1016/j.jenvman.2013.04.013

Malik, A., K.P. Singh, D. Mohan and D.K. Patel, 2004. Distribution of polycyclic aromatic hydrocarbons in Gomti River system, India. Bull. Environ. Contamin. Toxicol., 72: 1211-1218. DOI: $10.1007 / \mathrm{s} 00128-004-0372-6$

Malik, A., P. Verma, A.K. Singh and K.P. Singh, 2011. Distribution of polycyclic aromatic hydrocarbons in water and bed sediments of the Gomti River, India. Environ. Monit. Assess., 172: 529-545.

DOI: $10.1007 / \mathrm{s} 10661-010-1352-4$
Maskaoui, K., J.L. Zhou, H.S. Hong and Z.L. Zhang, 2002. Contamination by polycyclic aromatic hydrocarbons in the Jiulong River Estuary and Western Xiamen Sea, China. Environ. Poll., 118: 109-122. DOI: 10.1016/S0269-7491(01)00208-1

MEP, 2001. Discharge standard of pollutants for livestock and poulty breeding.

MEP, 2008. Discharge standard of water pollutants for pharmaceutical industry-chemical synthesis products category.

MEP, 2010. Environmental management method for new chemicals.

MEP, 2012. Environmental management and registration method for hazardous chemicals.

Mitra, S. and T.S. Bianchi, 2003. A preliminary assessment of polycyclic aromatic hydrocarbon distributions in the lower Mississippi River and Gulf of Mexico. Marine Chem., 82: 273-288. DOI: 10.1016/S0304-4203(03)00074-4

Montuori, P. and M. Triassi, 2012. Polycyclic aromatic hydrocarbons loads into the Mediterranean Sea: Estimate of Sarno River inputs. Marine Poll. Bull., 64: 512-520. DOI: 10.1016/j.marpolbul.2012.01.003

Moore, M.T., R. Schulz, C.M. Cooper, S. Smith Jr. and J.H. Rodgers Jr., 2002. Mitigation of chlorpyrifos runoff using constructed wetlands. Chemosphere, 46: 827-35. DOI: $10.1016 / \mathrm{S} 0045-6535(01) 00189-8$

MWR, 2015. Ministry of water resources of the people's Republic of China water resources bulletin.

NACWA, 2012 Pharmaceuticals in the water environment.

Nagy, A., G. Simon and I. Vass, 2012. Monitoring of Polycyclic Aromatic Hydrocarbons (PAHs) in surface water of the Hungarian upper section of the Danube River. Nova Biotechnol. et Chimica, 11: 27-36. DOI: 10.2478/v10296-012-0003-2

Nagy, A.S., G. Simon, J. Szabo and I. Vass, 2013. Polycyclic aromatic hydrocarbons in surface water and bed sediments of the Hungarian upper section of the Danube River. Environ. Monit. Assess., 185: 4619-31. DOI: $10.1007 / \mathrm{s} 10661-012-2892-6$

Nagy, P., J. Fekete and V.K. Sharma, 2007. Polycyclic Aromatic Hydrocarbons (PAHs) in surface waters of Rackevei-Soroksari Danube Branch, Hungary. J. Environ. Sci. Health, 42: 231-40. DOI: $10.1080 / 10934520601131318$

Nakada, N., K. Kiri, H. Shinohara, A. Harada and K. Kuroda et al., 2008. Evaluation of pharmaceuticals and personal care products as water-soluble molecular markers of sewage. Environ. Sci. Technol., 42: 6347-6353. DOI: 10.1021/es7030856 
Nie, M., C. Yan, W. Dong, M. Liu and J. Zhou et al., 2015. Occurrence, distribution and risk assessment of estrogens in surface water, suspended particulate matter and sediments of the Yangtze Estuary. Chemosphere, 127: 109-116.

DOI: $10.1016 /$ j.chemosphere.2015.01.021

NTP, 2011. Report on carcinogens, national toxicology program. Department of Health and Human Services.

Oaks, J.L., M. Gilbert, M.Z. Virani, R.T. Watson and C.U. Meteyer et al., 2004. Diclofenac residues as the cause of vulture population decline in Pakistan. Nature, 427: 630-633. DOI: 10.1038/nature02317

Ogbeide, O., I. Tongo and L. Ezemonye, 2015. Risk assessment of agricultural pesticides in water, sediment and fish from Owan River, Edo State, Nigeria. Environ. Monit. Assess., 187: 654-654. DOI: $10.1007 / \mathrm{s} 10661-015-4840-8$

Ohe, P.C.V.D. and V. Dulio, 2013. NORMAN prioritisation framework for emerging substances. Parc Technologique ALATA, VERNEUIL EN HALATTE, France.

Olujimi, O.O., O.S. Fatoki, J.P. Odendaal and A.P. Daso, 2012. Chemical monitoring and temporal variation in levels of endocrine disrupting chemicals (priority phenols and phthalate esters) from selected wastewater treatment plant and freshwater systems in Republic of South Africa. Microchem. J., 101: 11-23. DOI: 10.1016/j.microc.2011.09.011

Paiga, P., L.H. Santos, S. Ramos, S. Jorge and J.G. Silva et al., 2016. Presence of pharmaceuticals in the Lis river (Portugal): Sources, fate and seasonal variation. Sci. Total Environ., 573: 164-177. DOI: 10.1016/j.scitotenv.2016.08.089

Pathiratne, K.A., O.C. De Silva, D. Hehemann, I. Atkinson and R. Wei, 2007. Occurrence and distribution of Polycyclic Aromatic Hydrocarbons (PAHs) in Bolgoda and Beira Lakes, Sri Lanka. Bull. Environ. Contam. Toxicol., 79: 135-40.

DOI: $10.1007 / \mathrm{s} 00128-007-9092-\mathrm{Z}$

Patrolecco, L., N. Ademollo, S. Capri, R. Pagnotta, S. Polesello, 2010. Occurrence of priority hazardous PAHs in water, suspended particulate matter, sediment and common eels (Anguilla anguilla) in the urban stretch of the River Tiber (Italy). Chemosphere, 81: 1386-1392.

DOI: $10.1016 /$ j.chemosphere.2010.09.027

Pc, V.D.O., V. Dulio, J. Slobodnik, E. De Deckere and R. Kühne et al., 2011. A new risk assessment approach for the prioritization of 500 classical and emerging organic microcontaminants as potential river basin specific pollutants under the European water framework directive. Sci. Total Environ., 409: 2064-2077. DOI: 10.1016/j.scitotenv.2011.01.054
Peng, X., W. Ou, C. Wang, Z. Wang and Q. Huang et al. 2014. Occurrence and ecological potential of pharmaceuticals and personal care products in groundwater and reservoirs in the vicinity of municipal landfills in China. Sci. Total Environ., 490: 889-898. DOI: 10.1016/j.scitotenv.2014.05.068

Peng, X., Y. Yu, C. Tang, J. Tan and Q. Huang et al., 2008. Occurrence of steroid estrogens, endocrinedisrupting phenols and acid pharmaceutical residues in urban riverine water of the Pearl River Delta, South China. Sci. Total Environ., 397: 158-166. DOI: 10.1016/j.scitotenv.2008.02.059

Ramaswamy, B.R., G. Shanmugam, G. Velu, B. Rengarajan and D.G. Larsson, 2011. GC-MS analysis and ecotoxicological risk assessment of triclosan, carbamazepine and parabens in Indian rivers. J. Hazardous Mater., 186: 1586-1593.

DOI: $10.1016 /$ j.jhazmat.2010.12.037

Ravindra, K., R. Sokhi and R.V. Grieken, 2008. Atmospheric polycyclic aromatic hydrocarbons: Source attribution, emission factors and regulation. Atmos. Environ., 42: 2895-2921. DOI: 10.1016/j.atmosenv.2007.12.010

Regueiro, J., M. Llompart, C. Garcia-Jares, J.C. GarciaMonteagudo and R. Cela, 2008. Ultrasound-assisted emulsification-microextraction of emergent contaminants and pesticides in environmental waters. J. Chromatography A, 1190: 27-38. DOI: 10.1016/j.chroma.2008.02.091

Ribeiro, A.M., C.C. da Rocha, C.F. Franco, L.F. Fontana and A.D. Pereira Netto, 2012. Seasonal variation of polycyclic aromatic hydrocarbons concentrations in urban streams at Niteroi City, RJ, Brazil. Marine Poll. Bull., 64: 2834-2848. DOI: 10.1016/j.marpolbul.2012.09.014

Ribeiro, A.R., O.C. Nunes, M.F. Pereira and A.M. Silva, 2015. An overview on the advanced oxidation processes applied for the treatment of water pollutants defined in the recently launched Directive 2013/39/EU. Environ. Int., 75: 33-51.

DOI: 10.1016/j.envint.2014.10.027

Ribeiro, C., A.R. Ribeiro and M.E. Tiritan, 2016. Priority substances and emerging organic pollutants in Portuguese aquatic environment: A review. Rev. Environ. Contamin. Toxicol., 238: 1-44. DOI: $10.1007 / 398 \_2015 \_5006$

Roosens, L., A. Covaci and H. Neels, 2007. Concentrations of synthetic musk compounds in personal care and sanitation products and human exposure profiles through dermal application. Chemosphere, 69: 1540-1547.

DOI: 10.1016/j.chemosphere.2007.05.072

Rosal, R., I. Rodea-Palomares, K. Boltes, et al., 2010. Ecotoxicity assessment of lipid regulators in water and biologically treated wastewater using three aquatic organisms. Environ. Sci. Poll. Res. Int., 17: 135-144. DOI: 10.1007/s1 1356-009-0137-1 
Sanchez, J.A., M.S. Fernandez, J. Vicente and S. Lacorte, 2011. Development of a multi-residue method for the determination of organic micropollutants in water, sediment and mussels using gas chromatographytandem mass spectrometry. J. Chromatography A, 1218: 6799-6811.

DOI: $10.1016 /$ j.chroma.2011.07.056

Santhi, V.A. and A.M. Mustafa, 2013. Assessment of organochlorine pesticides and plasticisers in the Selangor River basin and possible pollution sources. Environ. Monit. Assess., 185: 1541-5154.

DOI: $10.1007 / \mathrm{s} 10661-012-2649-2$

Schwaiger, J., H. Ferling, U. Mallow, H. Wintermayr and R.D. Negele, 2004. Toxic effects of the nonsteroidal anti-inflammatory drug diclofenac: Part I: Histopathological alterations and bioaccumulation in rainbow trout. Aquatic Toxicol., 68: 151-166.

DOI: $10.1016 /$ j.aquatox.2004.03.014

Selvaraj, K.K., G. Sundaramoorthy and P.K. Ravichandran, 2015. Phthalate esters in water and sediments of the Kaveri River, India: Environmental levels and ecotoxicological evaluations. Environ. Geochem. Health, 37: 83-96.

DOI: 10.1007/s10653-014-9632-5)

Sha, Y., X. Xia, Z. Yang and G.H. Huang, 2006. Distribution of PAEs in the middle and lower reaches of the Yellow River, China. Environ. Monit. Assess., 124: 277-287. DOI: 10.1007/s10661-006-9225-6

Shanmugam, G., S. Sampath, K.K. Selvaraj, D.G. Larsson and B.R. Ramaswamy, 2014. Non-steroidal anti-inflammatory drugs in Indian rivers. Environ. Sci. Poll. Res., 21: 921-931.

DOI: $10.1007 / \mathrm{s} 11356-013-1957-6$

Sharpe, R.M., 2001. Hormones and testis development and the possible adverse effects of environmental chemicals. Toxicol. Lett., 120: 221-232. DOI: $10.1016 / \mathrm{S} 0378-4274(01) 00298-3$

Shaw, M., I.R. Tibbetts and J.F. Müller, 2004. Monitoring PAHs in the Brisbane River and Moreton Bay, Australia, using semipermeable membrane devices and EROD activity in yellowfin bream, Acanthopagrus australis. Chemosphere, 56: 237-246. DOI: 10.1016/j.chemosphere.2004.03.003

Shea, K.M., 2003. Pediatric exposure and potential toxicity of phthalate plasticizers. Pediatrics, 111: 1467-1478. DOI: $10.1542 /$ peds.111.6.1467

Shen, Y., X. Qian, X. Yin, M. Wang and N. Zhang et al., 2010. Determination and distribution features of phthalate esters in Xuanwu Lake. Nat. Sci. Edn., 40: 1337-1341.

DOI: 10.3969/j.issn.1001-0505.2010.06.040

Shi, Z., S. Tao, B. Pan, X.C. He and Q. Zuo et al., 2005. Contamination of rivers in Tianjin, China by polycyclic aromatic hydrocarbons. Environ. Poll., 134: 97-111. DOI: 10.1016/j.envpol.2004.07.014
Singh, S. and S.S. Li, 2011. Phthalates: Toxicogenomics and inferred human diseases. Genomics, 97: 148157. DOI: $10.1016 /$ j.ygeno.2010.11.008

Sirivithayapakorn, S. and K. Thuyviang, 2010. Dispersion and ecological risk assessment of $\mathrm{Di}(2-$ Ethylhexyl) Phthalate (DEHP) in the surface waters of Thailand. Bull. Environ. Contamin. Toxicol., 84: 503-506. DOI: 10.1007/s00128-010-9980-5

Sirivithayapakorn, S. and S. Limtrakul, 2008. Distribution coefficient and adsorption-desorption rates of Di(2-Ethylhexyl) Phthalate (DEHP) onto and from the surface of suspended particles in fresh water. Water Air Soil Poll., 190: 45-53. DOI: $10.1007 / \mathrm{s} 11270-007-9578-7$

Sirivithayapakorn, S.T.K., 2010. Dispersion and ecological risk assessment of $\mathrm{Di}(2$-Ethylhexyl) Phthalate (DEHP) in the surface waters of Thailand. Bull. Environ. Contam. Toxicol., 84: 503-506. DOI: $10.1007 / \mathrm{s} 00128-010-9980-5$

Slobodnik, J., L. Mrafkova, M. Carere, F. Ferrara and B. Pennelli et al., 2012. Identification of river basin specific pollutants and derivation of environmental quality standards: A case study in the Slovak Republic. Trends Analytical Chem., 41: 133-145. DOI: $10.1016 /$ j.trac.2012.08.008

Sousa, J., A.R. Ribeiro, M.O. Barbosa, M. Pereira and A. Silva, 2017. A review on environmental monitoring of water organic pollutants identified by EU guidelines. J. Hazardous Mater., 344: 1-13.

SPMP, 2001. Les cinq premiers secteurs utilisateurs de PVC en France en 2001. In: In Le PVC, données techniques.

Srinivasa, R.M., S. Basha, H.V. Joshi and G. Ramachandraiah, 2005. Seasonal distribution and contamination levels of total PHCs, PAHs and heavy metals in coastal waters of the Alang-Sosiya ship scrapping yard, Gulf of Cambay, India. Chemosphere, 61: 1587-1593.

DOI: $10.1016 /$ j.chemosphere.2005.04.093

Staal, Y.C., M.H. van Herwijnen, F.J. van Schooten and J.H. van Delft, 2006. Modulation of gene expression and DNA adduct formation in HepG2 cells by polycyclic aromatic hydrocarbons with different carcinogenic potencies. Carcinogenesis, 27: 646-655. DOI: 10.1093/carcin/bgi255

Staal, Y.C.M., D.G.A.J. Hebels, M.H.M.V. Herwijnen, R.W.H. Gottschalk and F.J.V. Schooten et al., 2007. Binary PAH mixtures cause additive or antagonistic effects on gene expression but synergistic effects on DNA adduct formation. Carcinogenesis, 28: 2632-2640. DOI: 10.1093/carcin/bgm 182

Stuerlauridsen, F., M. Birkved, L.P. Hansen, H.C. Holten Lützhøft and B. Halling-Sørensen, 2000. Environmental risk assessment of human pharmaceuticals in Denmark after normal therapeutic use. Chemosphere, 40: 783-793. DOI: 10.1016/S0045-6535(99)00453-1 
Stumpf, M., T.A. Ternes, R.D. Wilken, S.V. Rodrigues and W. Baumann, 1999. Polar drug residues in sewage and natural waters in the state of Rio de Janeiro, Brazil. Sci. Total Environ., 225: 135-141. DOI: $10.1016 / \mathrm{S} 0048-9697(98) 00339-8$

Sui, Q., B. Wang, W. Zhao, J. Huang and G. Yu et al., 2012. Identification of priority pharmaceuticals in the water environment of China. Chemosphere, 89: 280-286. DOI: 10.1016/j.chemosphere.2012.04.037

Suzuki, T., K. Yaguchi, S. Suzuki and T. Suga, 2001. Monitoring of phthalic acid monoesters in river water by solid-phase extraction and GC-MS determination. Environ. Sci. Technol., 35: 3757-3763. DOI: $10.1021 / \mathrm{es} 001860 \mathrm{i}$

Takashima, K., Y. Ito, F.J. Gonzalez and T. Nakajima, 2008. Different mechanisms of DEHP-induced hepatocellular adenoma tumorigenesis in wild-type and Ppar alpha-null mice. J. Occupat. Health, 50: 169-180. DOI: 10.1539/joh.L7105

Tanay, D.M., M. Kumar and I.S. Thakur, 2014. Differential toxicological endpoints of $\operatorname{Di}(2-$ Ethylhexyl) Phthalate (DEHP) exposure in MCF-7 and MDA-MB-231 cell lines: Possible estrogen receptor alpha (ERalpha) independent modulations. Indian J. Exp. Biol., 52: 1052-1061. PMID: 25434100

Teil, M.J., M. Blanchard, C. Dargnat, K. LarcherTiphagne and M. Chevreuil, 2007. Occurrence of phthalate diesters in rivers of the Paris district (France). Hydrol. Processes, 21: 2515-2525. DOI: $10.1002 /$ hyp.6484

TGA, 2008. Australian government, Department of Health and Aging, Therapeutic Goods Administration. Module 1, Administrative Information and Prescribing Information for Australia; Notice to Applicants; CTD-Module 1, TGA Edition.

Thomas, K.V. and M.J. Hilton, 2004. The occurrence of selected human pharmaceutical compounds in UK estuaries. Marine Poll. Bull., 49: 436-444.

DOI: 10.1016/j.marpolbul.2004.02.028

Tiedeken, E.J., A. Tahar, B. Mchugh and N.J. Rowan, 2017. Monitoring, sources, receptors and control measures for three European Union watch list substances of emerging concern in receiving waters A 20year systematic review. Sci. Total Environ., 574: 1140-1163. DOI: 10.1016/j.scitotenv.2016.09.084

Tijani, J.O., O.O. Fatoba, O.O. Babajide and L.F. Petrik, 2016. Pharmaceuticals, endocrine disruptors, personal care products, nanomaterials and perfluorinated pollutants: A review. Environ. Chem. Lett., 14: 27-49. DOI: 10.1007/s10311-015-0537-z

Tousova, Z., P. Oswald, J. Slobodnik, L. Blaha and M. Muz et al., 2017. European demonstration program on the effect-based and chemical identification and monitoring of organic pollutants in European surface waters. Sci. Total Environ., 601-602: 1849-1868. DOI: 10.1016/j.scitotenv.2017.06.032
Tran, B.C., M.J. Teil, M. Blanchard, F. Alliot and M. Chevreuil, 2015. BPA and phthalate fate in a sewage network and an elementary river of France. Influence of hydroclimatic conditions. Chemosphere, 119: 43-51. DOI: 10.1016/j.chemosphere.2014.04.036

Tsumura, Y., S. Ishimitsu, I. Saito, H. Sakai and Y. Tsuchida et al., 2003. Estimated daily intake of plasticizers in 1-week duplicate diet samples following regulation of DEHP-containing PVC gloves in Japan. Food Additives Contamin., 20: 317-324. DOI: 10.1080/0265203031000122021

Turner, R.E., E.B. Overton, B.M. Meyer, M.S. Miles and L. Hooper-Bui, 2014. Changes in the concentration and relative abundance of alkanes and PAHs from the Deepwater Horizon oiling of coastal marshes. Marine Poll. Bull., 86: 291-297.

DOI: 10.1016/j.marpolbul.2014.07.003

UNECE, 1998. The Aarhus protocol on Persistent Organic Pollutants (POPs).

UNEP, 2009. Stockholm convention on Persistent Organic Pollutants (POPs).

UNESCO, 2015. International initiative on water quality. United Nations Educational, Scientific and Cultural Organization, Paris, France.

USEPA, 1998. Effluent guidelines-pharmaceutical manufacturing point source category-permit guidance document by United State Environmental Protection Agency (USEPA).

USEPA, 2000. List of substances on IRIS. In: Integrated Risk System Information by United State Environmental Protection Agency (USEPA).

Veerasingam, S.A.A.M.M., 2013. Assessment of endocrine disruptors - DDTs and DEHP (plasticizer) in source water: A case study from Selangor, Malaysia. J. Water Health, 11: 311-323.

DOI: $10.2166 /$ wh.2013.151

Vieno, N.M., H. Harkki, T. Tuhkanen and L. Kronberg, 2007. Occurrence of pharmaceuticals in river water and their elimination in a pilot-scale drinking water treatment plant. Environ. Sci. Technol., 41: 5077-5084. DOI: 10.1021/es062720x

Wang, F., X. Xia and Y. Sha, 2008. Distribution of phthalic acid esters in Wuhan section of the Yangtze River, China. J. Hazardous Mater., 154: 317-324. DOI: $10.1016 /$ j.jhazmat.2007.10.028

Wang, L., G.G. Ying, J.L. Zhao, et al., 2010. Occurrence and risk assessment of acidic pharmaceuticals in the Yellow River, Hai River and Liao River of north China. Sci. Total Environ., 408: 3139-3147. DOI: $10.1016 /$ j.scitotenv.2010.04.047

Wang, L., Z. Yang, J. Niu and J. Wang, 2009. Characterization, ecological risk assessment and source diagnostics of polycyclic aromatic hydrocarbons in water column of the Yellow River Delta, one of the most plenty biodiversity zones in the world. J. Hazardous Mater., 169: 460-465. DOI: $10.1016 /$ j.jhazmat.2009.03.125 
Wang, Q., B.C. Kelly, 2016. Occurrence and distribution of synthetic musks, triclosan and methyl triclosan in a tropical urban catchment: Influence of land-use proximity, rainfall and physicochemical properties. Sci. Total Environ., 574: 1439-1447.

DOI: 10.1016/j.scitotenv.2016.08.091

Wang, Z., Y.S. Xin, W. Zhang, C. Hao and W. Xu et al., 2016. The effects of Di 2-Ethyl Hexyl Phthalate (DEHP) on cellular lipid accumulation in HepG2 cells and its potential mechanisms in the molecular level. Toxicol. Mechanisms Meth., 27: 245-252. DOI: $10.1080 / 15376516.2016 .1273427$

WFD, 2000. Directive of the European parliament and of the council 2000/60/EC establishing a framework for community action in the field of water policy. Official J., 22: 231-235.

WFD, 2013. Directive 2013/39/EU of the European parliament and of the council of 12 august 2013 amending Directives 2000/60/EC and 2008/105/EC as regards priority substances in the field of water policy. Official J., 226: 1-17.

WFD, 2015. Decision 495/2015/EU of 20 march 2015, establishing a watch list of substances for Unionwide monitoring in the field of water policy pursuant to Directive 2008/105/EC of the European parliament and of the council. Official J., 78: 40-42.

Wilkinson, J., P.S. Hooda, J. Barker, S. Barton and J. Swinden, 2017. Occurrence, fate and transformation of emerging contaminants in water: An overarching review of the field. Environ. Poll., 231: 954-970. DOI: $10.1016 / \mathrm{j}$.envpol.2017.08.032

Wolska, L., B. Zygmunt and J. Namieśnik, 2003. Organic pollutants in the Odra river ecosystem. Chemosphere, 53: 561-569.

DOI: 10.1016/s0045-6535(03)00368-0

Wu, C, X. Huang, J.D. Witter, A.L. Spongberg and K. Wang et al., 2014. Occurrence of pharmaceuticals and personal care products and associated environmental risks in the central and lower Yangtze river, China. Ecotoxicol. Environ. Safety, 106: 19-26. DOI: 10.1016/j.ecoenv.2014.04.029

Xie, S.L., M. Junaid, W.P. Bian, J.J. Luo and J.H. Syed et al., 2017. Generation and application of a novel transgenic zebrafish line $\operatorname{Tg}$ (cypla:mCherry) as an in vivo assay to sensitively monitor PAHs and TCDD in the environment. J. Hazardous Mater., 344: 723-732. DOI: 10.1016/j.jhazmat.2017.11.021

Xu, H., C. Li, Y. Li, G.H.B. Ng and C. Liu et al., 2015. Generation of $\operatorname{Tg}($ cypla:gfp) transgenic zebrafish for development of a convenient and sensitive in vivo assay for aryl hydrocarbon receptor activity. Marine Biotechnol., 17: 831-840.

DOI: $10.1007 / \mathrm{s} 10126-015-9669-1$
Xu, W., W. Yan, X. Li, Y. Zou and X. Chen et al., 2013. Antibiotics in riverine runoff of the Pearl River Delta and Pearl River Estuary, China: Concentrations, mass loading and ecological risks. Environ. Poll., 182: 402-407. DOI: $10.1016 /$ j.envpol.2013.08.004

Xu, Y., F. Luo, A. Pal, K.Y.H. Gin and M. Reinhard, 2011. Occurrence of emerging organic contaminants in a tropical urban catchment in Singapore. Chemosphere, 83: 963-969.

DOI: $10.1016 /$ j.chemosphere.2011.02.029

Yamagishi, T., T. Miyazaki, S. Horii, and K. Akiyama, 1983. Synthetic musk residues in biota and water from Tama River and Tokyo Bay (Japan). Arch. Environ. Contamin. Toxicol., 12: 83-89. DOI: 10.1007/BF01055006

Yan, J., J. Liu, X. Shi, X. You and Z. Cao, 2016. Polycyclic Aromatic Hydrocarbons (PAHs) in water from three estuaries of China: Distribution, seasonal variations and ecological risk assessment. Marine Poll. Bull., 109: 471-479. DOI: 10.1016/j.marpolbul.2016.05.025

Yang, Q.S., O.U. Su Ying, P. Xie, B.X. Mai and F.U. Jia Mo et al., 2004. Distribution and seasonal changes of Polycyclic Aromatic Hydrocarbons (PAHs) in surface water from Humen tidal channel. Acta Oceanologica Sinica.

Yang, Y., J. Fu, H. Peng, L. Hou and M. Liu et al., 2011. Occurrence and phase distribution of selected pharmaceuticals in the Yangtze Estuary and its coastal zone. J. Hazardous Mater., 190: 588-596. DOI: 10.1016/j.jhazmat.2011.03.092

You, L., V.T. Nguyen, A. Pal, H. Chen and Y. He et al., 2015. Investigation of pharmaceuticals, personal care products and endocrine disrupting chemicals in a tropical urban catchment and the influence of environmental factors. Sci. Total Environ., 536: 955-963. DOI: 10.1016/j.scitotenv.2015.06.041

Yu, L., J.C.W. Lam, Y. Guo, R.S.S. Wu and P.K.S. Lam et al., 2011a. Parental transfer of Polybrominated Diphenyl Ethers (PBDEs) and thyroid endocrine disruption in zebrafish. Environ. Sci. Technol., 45: 10652-10659. DOI: 10.1021/es2026592

Yu, Y., Q. Huang, Z. Wang, K. Zhang and C. Tang et al., $2011 \mathrm{~b}$. Occurrence and behavior of pharmaceuticals, steroid hormones and endocrine-disrupting personal care products in wastewater and the recipient river water of the Pearl River Delta, South China. J. Environ. Monit., 13: 871-878. DOI: $10.1039 / \mathrm{COEM} 00602 \mathrm{E}$

Yunker, M.B., R.W. Macdonald, R. Vingarzan, R.H. Mitchell and D. Goyette et al., 2002. PAHs in the Fraser River basin: A critical appraisal of PAH ratios as indicators of PAH source and composition. Organic Geochem., 33: 489-515. DOI: $10.1016 / \mathrm{S} 0146-6380(02) 00002-5$ 
Zhang, N., Y. Liu, V. Brink, O.R. Price and G.G. Ying, 2015. Ecological risks of home and personal care products in the riverine environment of a rural region in South China without domestic wastewater treatment facilities. Ecotoxicol. Environ. Safety, 122: 417-425.

DOI: 10.1016/j.ecoenv.2015.09.004

Zhang, R., W. Wang, X. Shi, X. Yu and M. Li et al., 2011. Health risk of semi-volatile organic pollutants in Wujin river inflow into Taihu Lake. Ecotoxicology, 20: 1083-1089.

DOI: $10.1007 / \mathrm{s} 10646-011-0682-5$

Zhang, S., Q. Zhang, S. Darisaw, O. Ehie and G. Wang, 2007. Simultaneous quantification of Polycyclic Aromatic Hydrocarbons (PAHs), Polychlorinated Biphenyls (PCBs), and Pharmaceuticals and Personal Care Products (PPCPs) in Mississippi river water, in New Orleans, Louisiana, USA. Chemosphere, 66: 1057-1069.

DOI: 10.1016/j.chemosphere.2006.06.067

Zhang, X., Y. Yao, X. Zeng, G. Qian and Y. Guo et al., 2008. Synthetic musks in the aquatic environment and personal care products in Shanghai, China. Chemosphere, 72: 1553-1558.

DOI: /10.1016/j.chemosphere.2008.04.039

Zhang, Y. and S. Tao, 2009. Global atmospheric emission inventory of Polycyclic Aromatic Hydrocarbons (PAHs) for 2004. Atmos. Environ., 43: 812-819. DOI: 10.1016/j.atmosenv.2008.10.050

Zhang, Y., C. Wang, L. Huang, R. Chen and Y. Chen et al., 2012. Low-level pyrene exposure causes cardiac toxicity in zebrafish (Danio rerio) embryos. Aquatic Toxicol., 114-115: 119-124.

DOI: $10.1016 /$ j.aquatox.2012.02.022
Zhang, Z., J. Huang, G. Yu and H. Hong, 2004. Occurrence of PAHs, PCBs and organochlorine pesticides in the Tonghui River of Beijing, China. Environ. Poll., 130: 249-261. DOI: $10.1016 / \mathrm{j}$.envpol.2003.12.002

Zhao, J.L., G.G. Ying, L. Wang, J.F. Yang and X.B. Yang et al., 2009. Determination of phenolic endocrine disrupting chemicals and acidic pharmaceuticals in surface water of the Pearl Rivers in South China by gas chromatography-negative chemical ionization-mass spectrometry. Sci. Total Environ., 407: 962-974. DOI: 10.1016/j.scitotenv.2008.09.048

Zhao, J.L., Q.Q. Zhang, F. Chen, L. Wang and G.G. Ying et al., 2013. Evaluation of triclosan and triclocarban at river basin scale using monitoring and modeling tools: Implications for controlling of urban domestic sewage discharge. Water Res., 47: 395-405. DOI: 10.1016/j.watres.2012.10.022

Zhou, X.F., C.M. Dai, Y.L. Zhang, R.Y. Surampalli and T.C. Zhang, 2011. A preliminary study on the occurrence and behavior of Carbamazepine (CBZ) in aquatic environment of Yangtze River Delta, China. Environ. Monit. Assess., 173: 45-53. DOI: $10.1007 / \mathrm{s} 10661-010-1369-8$

Zhoua, J.L. and K. Maskaouib, 2003. Distribution of polycyclic aromatic hydrocarbons in water and surface sediments from Daya Bay, China. Environ. Poll., 121: 269-281. DOI: $10.1016 / \mathrm{S} 0269-7491(02) 00215-4$

Zhu, L., B. Chen, J. Wang and H. Shen, 2004. Pollution survey of polycyclic aromatic hydrocarbons in surface water of Hangzhou, China. Chemosphere, 56: 1085-1095.

DOI: 10.1016/j.chemosphere.2004.05.025 